\title{
Modelling long-term alluvial-peatland dynamics in temperate river floodplains
}

\author{
Ward Swinnen $^{1,2}$, Nils Broothaerts ${ }^{1}$, and Gert Verstraeten ${ }^{1}$ \\ ${ }^{1}$ Department of Earth and Environmental Sciences, KU Leuven, Leuven, 3000, Belgium \\ ${ }^{2}$ Research Foundation - Flanders (FWO), Brussels, 1000, Belgium \\ Correspondence: Ward Swinnen (ward.swinnen@kuleuven.be)
}

Received: 19 May 2021 - Discussion started: 7 June 2021

Revised: 13 October 2021 - Accepted: 13 October 2021 - Published: 1 December 2021

\begin{abstract}
Peat growth is a frequent phenomenon in European river valleys. The presence of peat in the floodplain stratigraphy makes them hotspots of carbon storage. The long-term dynamics of alluvial peatlands are complex due to interactions between the peat and the local river network, and as a result, alluvial-peatland development in relation to both regional and local conditions is not well understood. In this study, a new modelling framework is presented to simulate long-term peatland development in river floodplains by coupling a river basin hydrology model (STREAM - Spatial Tools for River basins and Environment and Analysis of Management options) with a local peat growth model (modified version of DigiBog). The model is applied to two lowland rivers in northern Belgium, located in the European loess (Dijle (Dyle) River) and sand (Grote Nete River) belts. Parameter sensitivity analysis and scenario analysis are used to study the relative importance of internal processes and environmental conditions on peatland development. The simulation results demonstrate that the peat thickness is largely determined by the spacing and mobility of the local river channel(s) rather than by channel characteristics or peat properties. In contrast, changes in regional conditions such as climate and land cover across the upstream river basin have been shown to influence the river hydrograph but have a limited effect on peat growth. These results demonstrate that alluvial-peatland development is strongly determined by the geomorphic boundary conditions set by the river network and as such models must account for river channel dynamics to adequately simulate peatland development trajectories in valley environments.
\end{abstract}

\section{Introduction}

In many river systems throughout Europe, peat can be found in the Holocene floodplain stratigraphy (Notebaert and Verstraeten, 2010). The development of peat and organic-rich floodplain deposits is associated with low-energy floodplain environments and limited sediment dynamics (Candel et al., 2017). Active peat growth occurred mostly during the early Holocene and has disappeared at many locations due to anthropogenic land cover change since the Neolithic and its effect on the landscape sediment dynamics (Broothaerts et al., 2014b; Swinnen et al., 2020). While these have been studied as environmental archives, the dynamics of alluvial peat formation and its interaction with the local geomorphology, sediment dynamics, hydrology and human impact are not fully understood (e.g. Comas et al., 2004). Most available case studies on floodplain peatlands cluster in tropical and boreal regions where human impact only occurred in more recent time periods and mainly involves geomorphic and stratigraphic reconstructions (e.g. Boucher et al., 2006; Householder et al., 2012; Kumaran et al., 2016; Mann et al., 2010).

Nevertheless, temperate river floodplains can store large amounts of organic carbon and contribute disproportionally to the total terrestrial carbon stock, often due to the presence of peat (Sutfin et al., 2016; Wohl et al., 2012). In recent times, floodplain environments have been increasingly used as multi-functional systems, providing a range of services such as flood retention, nature conservation and carbon storage (Brown et al., 2018). As such, a good understanding of the dynamics of alluvial peatlands in interaction with the complex nature of floodplain environments is crucial, not only to protect both active and buried peat but also to bal- 
ance the different functions and services of a floodplain under changing climatic and anthropogenic conditions (Brown et al., 2018; van Diggelen et al., 2006; Notebaert and Verstraeten, 2010). Process-based peatland modelling studies on these environments are not available and can be a useful tool in studying the interaction between peatland development and the environment, both on a local and on a river basin scale. A peatland model specifically designed for an alluvial setting would allow us to study these environments under a range of conditions, which is more difficult using only the traditional stratigraphic and multi-proxy reconstructions. For other peatland types such as raised bogs and blanket peatlands, the modelling of their long-term dynamics has demonstrated the added value of process-based models in improving our understanding of peatland development and its sensitivity to both internal and external factors (Frolking et al., 2010; Morris et al., 2011; Yu et al., 2001a).

Several local peat growth models have been developed over the past decades with varying degrees of complexity and focus mostly on raised bogs or general peat processes (Frolking et al., 2010; Hilbert et al., 2000; Morris et al., 2012). A frequently used model type is the cohort model, in which a peatland is represented by a peat column where each layer or cohort corresponds to the biomass deposited in a specific year (Baird et al., 2012; Frolking et al., 2010; Heinemeyer et al., 2010). This model structure allows us to simulate peat growth at an annual resolution over millennial timescales and allows us to track and update specific peat properties trough time. One of the most recent and widely applied cohort models is the DigiBog model, which incorporates a variety of hydrological and ecohydrological feedbacks (Morris et al., 2011). The model has been frequently used to study peatland behaviour both in temperate and tropical environments (Baird et al., 2017; Kelly et al., 2014; Young et al., 2017, 2019). However, these models are not directly applicable to an alluvial setting. The assumption can be made that most of the basic concepts of raised bog development are also valid for alluvial peatlands, but even then, several changes will have to be made to these models to make them representative of an alluvial context. Firstly, most peatland models assume the peat column to be ombrotrophic and as such do not simulate water fluxes between the surrounding landscape and the peat layer. In river floodplains, this assumption cannot be made because of the hydrological interaction of the peat layer with the river channel(s) and groundwater. In contrast to several other peatland types, the water fluxes feeding alluvial peatlands can be diverse and include both local and regional sources. As the water fluxes interacting with the alluvial peatland can originate from the entire upstream river basin, all factors influencing the river basin hydrology such as climate and land cover can potentially influence alluvialpeatland dynamics. Secondly, the peat-forming environments in an alluvial context show a wide variety of vegetation types, which can range from a combination of mosses and sedges to carr forests, which is less the case for raised bogs.
Alluvial peatlands and the local river network can be assumed to co-evolve and should thus be considered a peatland-stream complex. However, research on peatland streams has focussed mainly on their role in the carbon cycle, but understanding their geomorphology and channel morphodynamics has been more speculative (Billett et al., 2004; Candel et al., 2017; Juutinen et al., 2013; Watters and Stanley, 2007). Several conceptual models describing the development of the stream network in peat-forming floodplains have been put forward, but currently, both the number of available case studies and our understanding of the channel dynamics in alluvial peatlands is limited (Broothaerts et al., 2013; Candel et al., 2017; Lespez et al., 2015a; Nanson, 2009). Given the combination of both local and regional factors influencing alluvial-peatland dynamics, the development of a modelling framework requires a combination of a local peat growth model incorporating the characteristics of the local river network and a regional hydrology model.

Here, we present a coupled alluvial-peatland-river-basin hydrology model which is able to simulate alluvial-peatland dynamics over Holocene timescales. Given the complexity of the studied environment and the limited available data and knowledge on alluvial peatlands, a scenario-based approach is used here, varying climatic conditions, land cover and river channel properties, which allows us to explore the effect of different processes on the long-term development of alluvial peatlands. The aim of this article is thus to provide insight into the sensitivity of these systems to changes in external factors and to identify the key processes governing the evolution of alluvial peatlands.

\section{Methodological overview}

In this article, a new modelling framework is presented, specifically designed to simulate peatland dynamics in alluvial environments over Holocene timescales. The framework consists of a coupling between the DigiBog peatland model and the STREAM (Spatial Tools for River basins and Environment and Analysis of Management options) river basin water balance model. Modifications are made to DigiBog to make it more applicable to alluvial environments. These changes encompass a different shape of the peat body and algorithmic changes to the calculation of the biomass productivity and evapotranspiration. STREAM is selected as a regional hydrology model due to its simplicity but is still able to simulate the river basin water balance under various conditions (Aerts et al., 1999; Morris et al., 2011). The model has been successfully applied to river basins across the globe, simulating palaeohydrology and river basin water balances (Aerts et al., 2006; Notebaert et al., 2011; Renssen et al., 2007; Ward et al., 2008). Both models are calibrated based on available field data consisting of river discharge time series and measured peat properties. The coupling between both models is made by using the river discharge sim- 


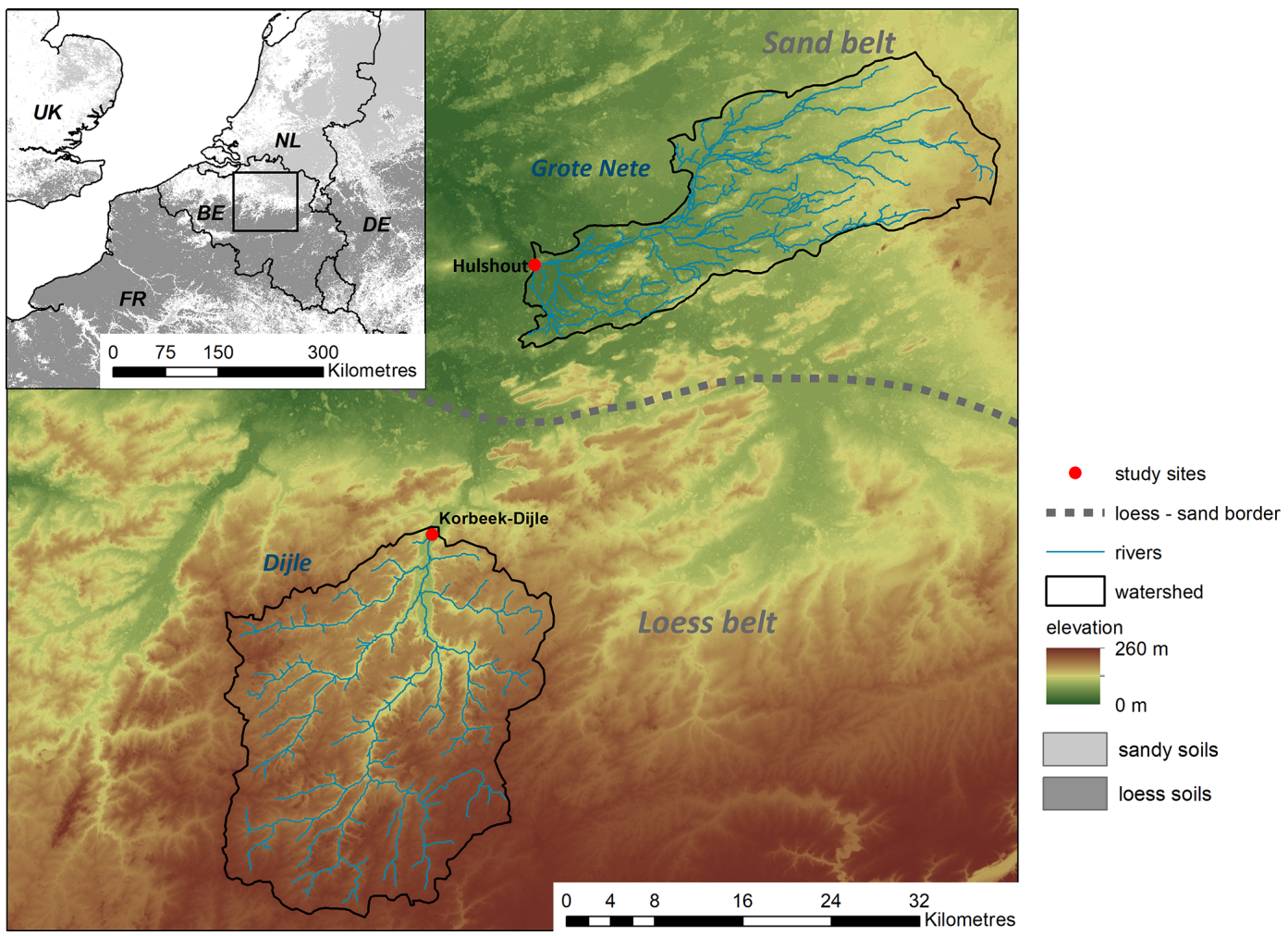

Figure 1. Location of the two studied river basins (Dijle and Grote Nete), with indications of the floodplain study sites and the border between the sand and loess belts. The mapping of the sandy and loess soils is derived from the Topsoil physical properties for Europe dataset (ESDAC) (Ballabio et al., 2016).

ulated by STREAM as a hydrological boundary condition for the local peat growth model. In a first analysis, the sensitivity of alluvial peat growth to internal dynamics and local climate and land cover conditions is studied by doing an OAT (one-at-the-time) sensitivity analysis for the modified DigiBog model. Secondly, scenario analysis is used to study the dynamics of alluvial peatlands in relation to river channel properties/dynamics and regional climate and land cover conditions. For this purpose, the coupled STREAMDigiBog model is applied to the Dijle (Dyle) River and Grote Nete River basins in northern Belgium. These two cases are selected because of their contrasting hydrology, welldocumented floodplain stratigraphy and landscape history and can serve as representative case studies for the European loess and sand belts covering large parts of the European lowlands.

\section{Study area and field data}

The study area consists of two river basins located in northern Belgium (Fig. 1). The Dijle River basin $\left(742 \mathrm{~km}^{2}\right)$ is situated at the northern edge of the European loess belt and drains an undulating plateau with elevations ranging between 25 and 165 ma.s.l. The geology consists of Palaeogene and
Neogene clays and sands overlain by Pleistocene loess (Herbosch and Verniers, 2013). The soils in the floodplain consist mainly of Fluvisols and Gleysols, while the hillslope is covered by Luvisols (Dondeyne et al., 2014). The current land use is dominated by arable land $(41 \%)$, grassland $(18 \%)$ and built-up land (26\%). The Holocene geomorphic dynamics of the Dijle River have been studied in detail using both modelling and field-based techniques (De Brue and Verstraeten, 2014; Notebaert et al., 2009; Van Oost et al., 2012). Palynological studies in the floodplains of the Dijle show that the river basin was largely forested during the first half of the Holocene (Mullenders et al., 1966; Mullenders and Gullentops, 1957; De Smedt, 1973). Significant indications of human impact are seen from the Bronze Age onwards ( 3.9 cal kyr BP), with a gradual opening of the vegetation and an increase in the area under cropland during the Roman period (Broothaerts et al., 2014c). The Dijle River saw widespread peat growth during the early Holocene but has almost no active peat growth today. The floodplain deposits are generally thick, with the organic-rich layers mostly covered by overbank sedimentation from the Roman period onwards following soil erosion on the deforested hillslopes (Broothaerts et al., 2014a; Swinnen et al., 2020). The case of the Dijle River can be used as a model for many river systems in temperate climates, where floodplain peat deposits 
were covered by mineral sediment due to anthropogenic land cover change and increased erosion rates (Notebaert and Verstraeten, 2010; Treat et al., 2019; Walter and Merritts, 2008).

The Grote Nete River basin $\left(561 \mathrm{~km}^{2}\right)$ is situated at the southern side of the European sand belt. The river basin drains the Campine Plateau, consisting of middle Pleistocene fluvial sands and gravels (Beerten et al., 2017; Gullentops et al., 2001). The most frequent soil types consist of Arenosols, Podzols and Plaggic Anthrosols (Dondeyne et al., 2014). The current land cover consists mainly of grassland $(48 \%)$, forest $(21 \%)$ and built-up land $(27 \%)$. Traces of agriculture in the region date back to $5.45 \mathrm{cal}$ kyr BP, but farming is assumed to have been limited to a few isolated locations until the Middle Ages due to the relatively infertile soils (Goedseels and Vanhautte, 1983; Goossens and Riksen, 2009). The Holocene floodplain stratigraphy of the Grote Nete River is relatively thin, with a mean thickness of around $1.5 \mathrm{~m}$, and highly variable, with alternating layers of channel deposits, peat and overbank deposition (Swinnen et al., 2020). Peat cutting for household fuel has been documented for the region, but the effect of this activity on the alluvial stratigraphy has not yet been quantified (Burny, 1999).

Available field data for the two river basins can be used to constrain specific model parameters and serve as external validation of the model simulations. A dataset on peat thickness and properties, derived from soil corings across the study areas, provides a mean dry bulk density for the alluvial peat deposits in the loess and sand belts (Swinnen et al., 2020). The measured peat thickness and bulk density values are corrected for compaction due to burial by mineral sediment. The compaction percentage is calculated using an empirical relationship expressing the percentage of thickness reduction as a function of the effective stress of the overlying sediment (Van Asselen et al., 2010; Swinnen, 2020). Details on the calculation of the compaction-corrected peat thickness and dry bulk density values are given in Sect. A3 in the Appendix. The mean and range in the observed compactioncorrected peat thickness values are used as a reference for the results of the sensitivity analysis and scenario simulations. As such, they can be used to identify which model scenarios correspond with the observed peat thickness. The compaction-corrected dry bulk density data are used to set the dry bulk density model parameter value to the measured mean value.

\section{Model development}

To simulate the development of alluvial peatlands at Holocene timescales, a modelling framework is developed by coupling a local peat growth model with a river basin hydrology model (Fig. 2). The local model domain consists of a floodplain cross section with a flat impermeable substrate layer on top of which peat can grow. The peat layer is assumed to develop as an elliptic bog located between straight adjacent channels. The local peatland model consists of a modified version of the DigiBog peatland model which simulates a 1D peat profile at the centre of the bog. The entire floodplain width is assumed to be covered by peat, with the river channel(s) spaced equally over the cross section (Fig. 3). The cross-section locations are assumed to be situated at the outlet of the studied river basins, which corresponds to the localities of Korbeek-Dijle (Dijle River) and Hulshout (Grote Nete River) (Fig. 1). The water level in the river channels is simulated by the STREAM basin hydrology model and serves as a lateral boundary condition for the local peat growth model (Fig. 2). All dates related to the model simulations are reported as calendar years $\mathrm{BC} / \mathrm{BCE}$. All dates originating from radiocarbon dating are reported as $\mathrm{BP} / \mathrm{calBP}$.

\subsection{Local peatland model}

The alluvial peat growth is modelled using a modified version of the DigiBog model (Morris et al., 2011). To calculate the water table dynamics, Childs' equation for an elliptic bog is used with the length of the ellipse (parallel to the direction of the river channel flow) being infinitely long relative to the width (Fig. 3) (Childs, 1969). Additionally, changes were made to the calculation of the potential and actual evapotranspiration rates because of the important differences in vegetation type between raised bogs and alluvial peatlands. The annual potential evapotranspiration rate is calculated using the Thornthwaite equation based on mean monthly temperatures because of its relative simplicity and the low amount of input data needed (Moeletsi et al., 2013). The potential evapotranspiration rate is subdivided in soil evaporation and plant transpiration rates based on the leaf area index (Williams et al., 1983). The actual evapotranspiration rates are calculated based on the water table depth, plant rooting depth and Ellenberg indicator value for moisture ( $f$ value). As such, the local vegetation characteristics are taken into account (see Sect. A2 in the Appendix for details).

The biomass productivity equation used in the original DigiBog model is constructed for typical bog-building species such as Sphagnum mosses. Here, the net primary productivity is calculated using the Thornthwaite Memorial equation, which does not assume the presence of a specific vegetation type and has been successfully applied in other peatland models (Heinemeyer et al., 2010). The Thornthwaite Memorial equation has been constructed for global applications and thus allows for a wider variety of vegetation types (Lieth and Box, 1972). Since the actual evapotranspiration rate is dependent on both the water table depth and vegetation characteristics, the peatland vegetation indirectly also influences the calculated biomass productivity. 


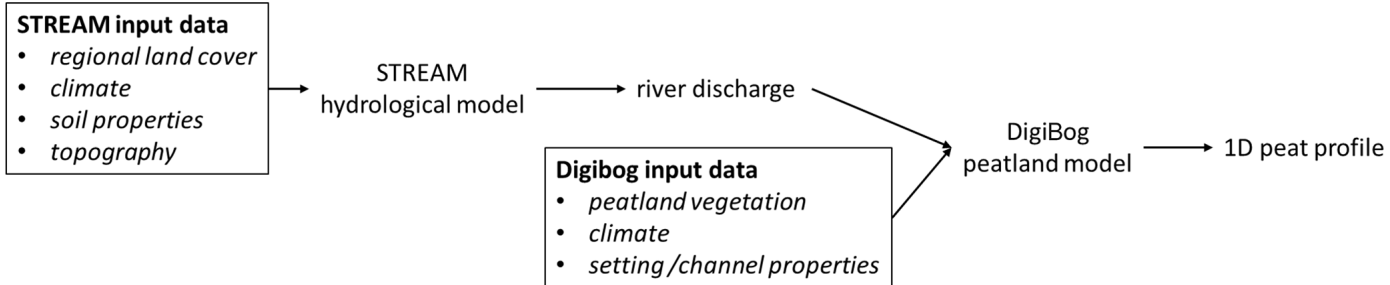

Figure 2. General model workflow. For a more detailed description of the model structure, the reader is referred to the text.

(a)

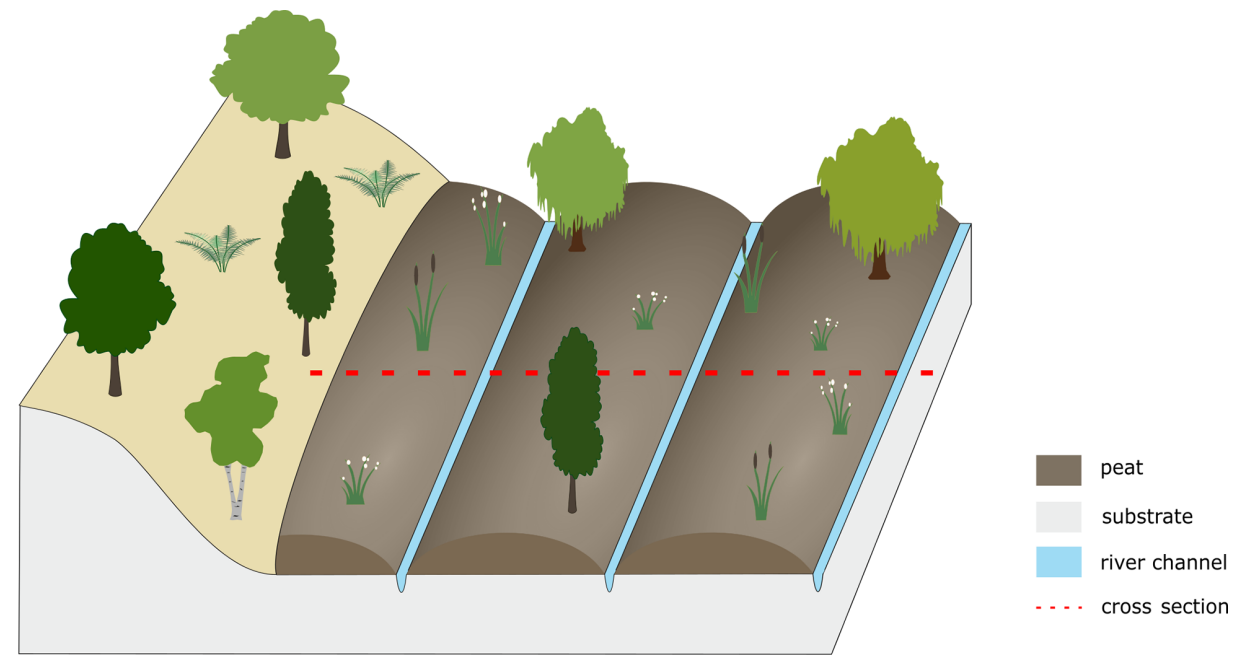

(b)

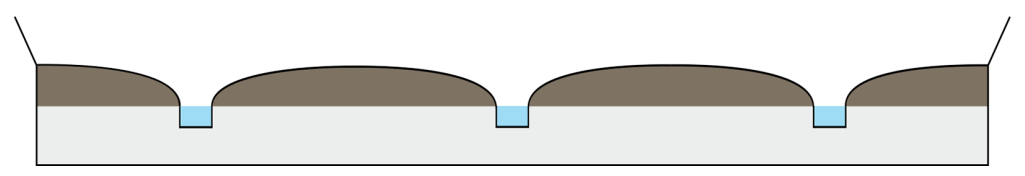

Figure 3. Conceptual drawing of the model domain. (a) Landscape setting of the alluvial peatland, represented by elliptic bogs on top of an impermeable substrate with straight river channels. The red dotted line indicates the cross-sectional location. (b) Schematic floodplain cross-sectional drawing. The 1D model simulates the peat profile at the centre of a single elliptic bog.

\subsection{River basin hydrology model}

The river basin hydrology is modelled using STREAM, which is a grid-based, spatially distributed water balance model (Aerts et al., 1999). In STREAM, the hydrological cycle of a basin is simulated on a raster, where each grid cell consists of a set of fluxes and reservoirs. Water is added to the system by precipitation. Rainfall can either contribute directly to the discharge as surface runoff or be added to the soil reservoir. When temperatures at a certain location are below $0{ }^{\circ} \mathrm{C}$, the precipitation is added to the snow reservoir. This reservoir can contribute to the precipitation through snowmelt using a degree day factor model. When the precipitation reaches the soil surface, the amount of generated runoff is calculated using the curve number approach, making the runoff amount dependent on the soil type and land cover. The water that enters the soil is added to the soil reservoir as long as the soil water content is below the field capacity. Otherwise, it flows to the deep groundwater reservoir. The contribution of the soil and groundwater reservoirs to the total discharge is dependent on the amount of water stored in the reservoir at each location, a calibration parameter and the local slope (Aerts and Bouwer, 2003). Each grid point can thus contribute water to the basin discharge using three different pathways (surface runoff, soil throughflow and groundwater flow). The total discharge of all grid points is accumulated using a flow accumulation algorithm. As such, the discharge is not routed explicitly through the landscape but is assumed to accumulate according to the flow network at the surface and to leave the river basin at the outlet (Aerts and Bouwer, 2003) (details on the use of STREAM 
and the calibration procedure are given in Sect. A1 in the Appendix).

\subsection{Coupling the STREAM and modified DigiBog models}

The daily discharge time series simulated by STREAM are used as a lateral boundary condition for the adapted DigiBog model. The total discharge is divided equally over all river channels and converted to water levels using Manning's equation. The position of the channel(s) is assumed to be fixed. As a consequence, the lateral extent of the peatland is assumed to remain constant over the entire simulation period. This approach thus ignores the process of peat erosion by lateral channel migration. While this probably does not match with reality, peat erosion was not included for the sake of simplicity. This might potentially lead to an overestimation of the peat thickness for locations where a significant part of the profile was eroded during the Holocene. However, the available radiocarbon dates for the alluvial peatlands in the Dijle and Grote Nete basins indicate that several floodplain locations were able to develop continuous Holocene peat records without significant peat removal by channel migration (Broothaerts et al., 2014b; Swinnen et al., 2020). When simulating the peatland development, the dischargewater level relationship changes over time for discharges above the bankfull stage due to changes in the peat surface elevation. As a result, this relationship is updated every time step. To apply Manning's equation, roughness values of 0.035 for the channels and 0.068 for the floodplain surface were used (Hosia, 1980; Lappalainen et al., 2010; Marttila et al., 2012; Medeiros et al., 2012a; Thomas and Nisbet, 2007; Tuukkanen et al., 2012). The floodplain slope is determined by calculating the mean floodplain gradient over a distance of $1000 \mathrm{~m}$ up- and downstream of the studied location using lidar elevation data with a $1 \mathrm{~m}$ resolution. The assumption is made that the floodplain slope at a specific location did not change significantly throughout the Holocene. Since there is no significant relationship between Holocene floodplain stratigraphy thickness and catchment area for both the Dijle and Grote Nete rivers, the current floodplain slope can be assumed to be representative for the entire Holocene. The local peat growth model simulates peatland development at millennial timescales, but due to computational limitations, this was not possible for STREAM. To overcome this issue, the river basin hydrology was simulated for a 100 -year period, and the model output is repeated every 100 years until the simulation time of the local peat growth model is met.

\section{Model applications}

\subsection{Sensitivity analysis}

First of all, an OAT (one-at-the-time) sensitivity analysis was performed for the modified DigiBog model by varying the different model parameters over a specified range, which is determined by a review of the literature. Only the parameter under consideration is varied stepwise over $75 \%$ of the range mentioned in the literature, while all others are kept at their standard value (a detailed table with the simulated range for each of the parameters is listed in Sect. A4 in the Appendix). The local peatland model is run under conditions typical for the alluvial peatlands in northern Belgium for a time period of 10000 years, which is sufficiently long to reach a peat thickness in equilibrium with the simulated conditions. The sensitivity was analysed based on the peat thickness at the end of the simulation period. Parameter values for the calculation of the potential and actual evapotranspiration rates are derived from the literature. Due to the limited values available, these parameters are not included in the sensitivity analysis. The model domain of the 1D DigiBog model only includes the peat layer, with boundary conditions set by the impermeable substrate and the water level in the adjacent channels. However, in an alluvial setting, the peat hydrology can be influenced by external factors such as channel network geometry and river basin hydrology. To test the sensitivity of the model to external hydrological factors, two additional parameters were varied. Firstly, the substrate below the peat was no longer assumed to be impermeable, but an additional vertical water flux was incorporated, representing the effect of a hydrological interaction between the peat and its substrate in both the upward and downward direction. This flux is incorporated as an additional source or sink term, similar to the precipitation. Secondly, the effect of changes in the lateral extent of the peat layer was studied. The lateral extent specifies the distance between the channel and the centre of the peat body and is thus determined by the number of channels in a floodplain cross section and their spacing.

The results of the OAT sensitivity analysis indicate a moderate impact of peat properties on the final peat thickness after 10000 years of simulation, ranging from 1.46 to $3.56 \mathrm{~m}$ (Fig. 4a). Variations in the oxic decomposition rate result in a decrease in the final peat thickness for increasing rates, although the effect is relatively limited in comparison to other variables. The anoxic-decomposition rate does not strongly influence the thickness, except for very low values of anoxic decomposition, which lead to lower peat thickness values. This can probably be attributed to the relationship between the degree of decomposition and the hydraulic conductivity of the peat, where low anoxic-decomposition rates lead to higher conductivity values, increasing the exposure of the peat column to oxic conditions. With respect to the physical properties, the peat thickness is mostly influenced by the dry bulk density and the $a$ parameter of the hydraulic conductivity relationship (especially in the lower part of the simulated range). The $a$ parameter determines the conductivity for highly decomposed peat. Since most of the peat profile consists of well-decomposed peat, this parameter determines the capacity of the peat column to keep itself water saturated. As 

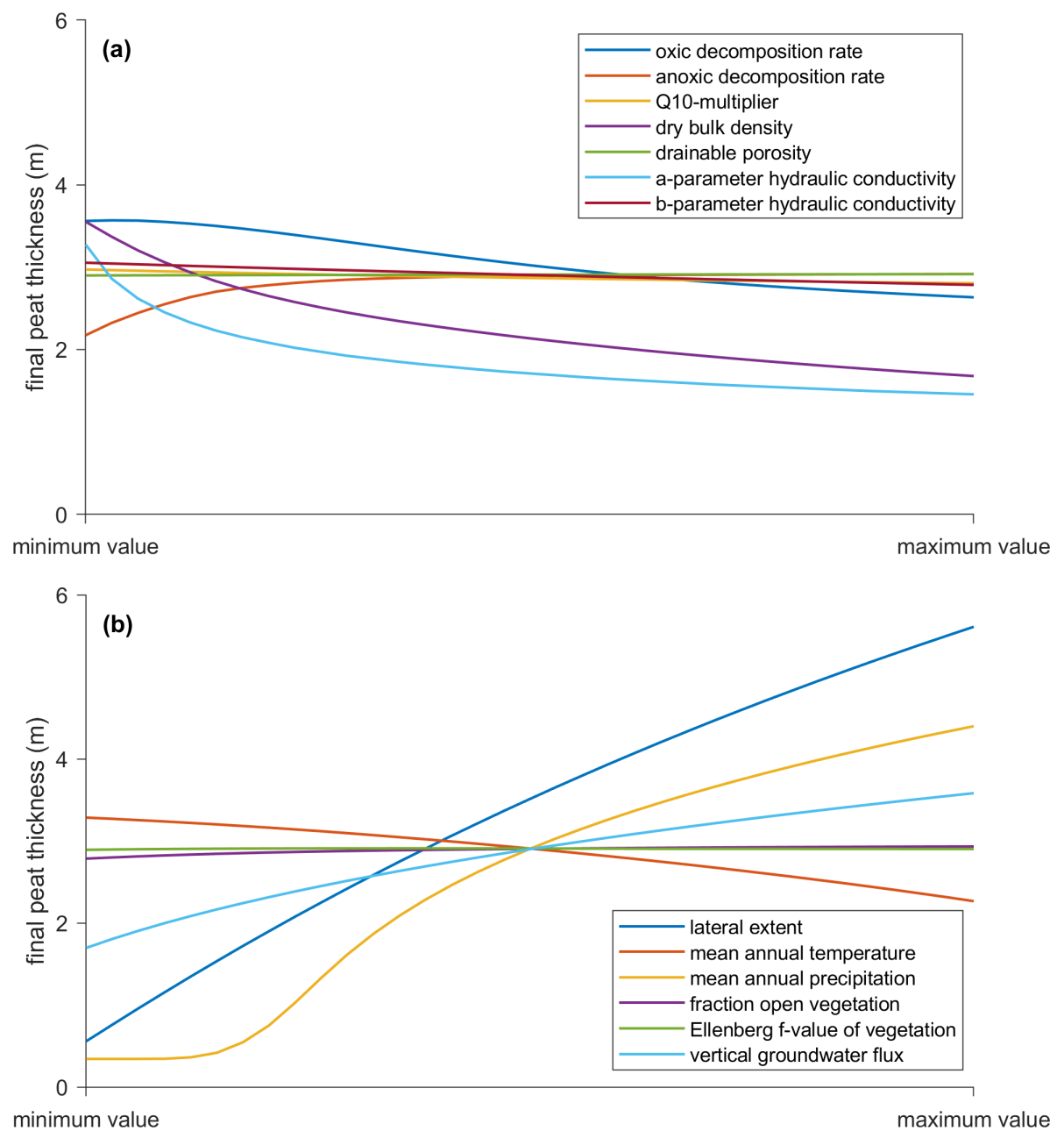

Figure 4. Final peat thickness (m) for (a) all variables used in the one-at-a-time (OAT) parameter sensitivity test for model parameters related to peat properties and (b) external factors including the peatland vegetation, climatic conditions and hydrology. Each parameter is varied over the range mentioned in Table A6 in the Appendix.

a result, low values for the $a$ parameter lead to higher final thickness values.

The climatic variables, on the other hand, have a stronger effect on the simulated peat thickness, with a strong positive relationship with the mean annual precipitation and a slight negative relationship with the mean annual temperature (Fig. 4b). This indicates that the increased biomass productivity due to higher temperatures does not compensate the negative effects of a higher temperature (increased evapotranspiration and decomposition rates) on the simulated peat thickness.

In contrast to the climatic conditions, the parameters related to the local floodplain vegetation (fraction of open vegetation and Ellenberg $f$ value) have a much smaller effect on the peat thickness. Overall, a tree-rich vegetation type appears to have a slight positive effect on the final peat thickness in comparison to an open vegetation type, suggesting that the increased biomass productivity of trees more than compensates the increase in plant transpiration. The two model parameters related to the hydrological setting of the alluvial peatland (lateral extent and vertical groundwater flux) generally result in the largest differences in the final peat thickness. An upward vertical flux from the substrate to the peat layer results in an increased peat thickness due to the increased amount of water feeding the peat layer. The lateral extent is positively correlated with the final thickness. A larger distance between the channels lowers the slope of the groundwater mound in the peat layer, reducing the drainage efficiency.

\subsection{Local peatland model}

A first model application focusses on local alluvial-peatland dynamics, i.e. without taking into account the effect of the river basin hydrology and river channel dynamics. This local peatland model is applied to the locations of KorbeekDijle and Hulshout and runs from 10.05 kyr BCE until now, 

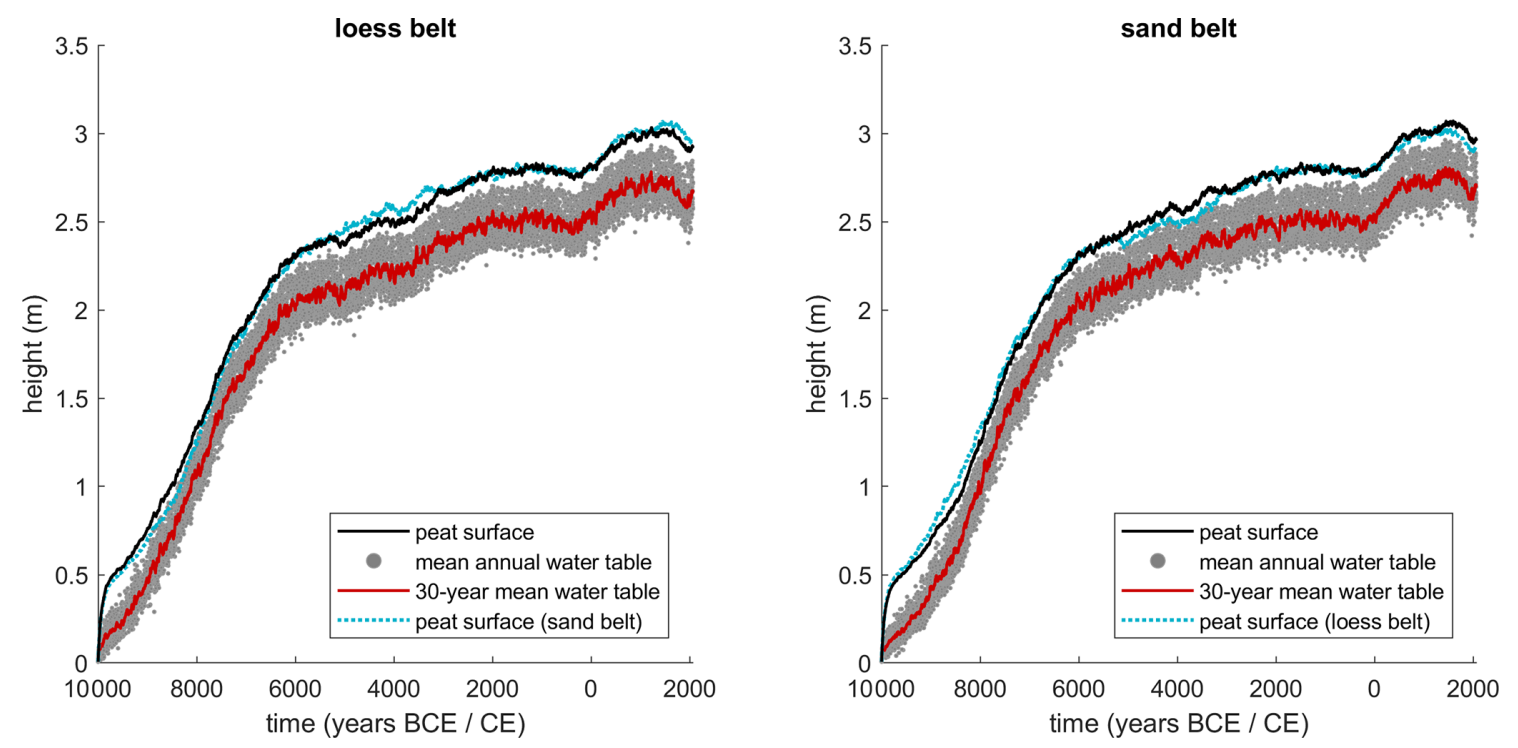

Figure 5. Simulated evolution of an alluvial peatland for both the loess and sand belts since $10.05 \mathrm{kyr}$ BCE.

assuming a fixed water level in the channels at the level of the substrate, with a channel spacing of $200 \mathrm{~m}$. The vegetation on top of the peat profile is assumed to be a mixture of trees and open vegetation, each accounting for $50 \%$ of the areal cover. Time series for temperature and precipitation were constructed using a pollen-based climate reconstruction with a spatial resolution of $1^{\circ} \times 1^{\circ}$ and a temporal resolution of 500 years, expressed as anomalies relative to the year 1850 CE (Mauri et al., 2015). Annual time series were constructed by randomly selecting daily time series with a length of 1 year from the 30-year climatic period around the year $1850 \mathrm{CE}$ for the station of Ukkel (Belgium). The time series were corrected in such a way that the mean value matches the pollen-based climate reconstructions. Random variability was added to the mean annual value, which is equal to the observed standard deviation for the period 1835-1864 in Ukkel. For the mean annual precipitation amount and mean annual temperature, the relative and absolute standard deviation were used, respectively.

The simulated peat thickness evolution shows a phase of rapid peat growth up to 2 to $2.5 \mathrm{~m}$ between 10.05 and $6.05 \mathrm{kyr}$ BCE, after which a much lower growth rate leads to final peat thicknesses of approximately $3 \mathrm{~m}$ by the Middle Ages (Fig. 5). The loess belt (Dijle) and sand belt (Grote Nete) show a similar peatland development trajectory, with some minor differences, which can be attributed to slightly different Holocene climate reconstructions for both regions. The similarity between both trajectories, however, does not match the observed differences in floodplain stratigraphy as derived from field data (Swinnen et al., 2020). The floodplain stratigraphy of the Dijle River shows a clear transition from alluvial peatlands to mineral overbank sedimentation with a mean compaction-corrected peat thickness of $1.6 \mathrm{~m}$. In con- trast, the Grote Nete floodplain stratigraphy is highly variable with alternating layers of peat, organic-rich sediments and mineral sediment and a lower mean peat thickness of $0.56 \mathrm{~m}$.

\subsection{Environmental conditions and river network characteristics}

In a next step, the calibrated STREAM model was applied to the Dijle River and Grote Nete River basins, taking into account changes in river basin hydrology following climate and land use change. The climate scenarios are constructed in such a way that they cover the entire range of temperatureprecipitation combinations, as were present during the period $12 \mathrm{cal} \mathrm{kyr}-100 \mathrm{calBP}$. Five points were selected along the climate trajectory of both river basins as derived from the pollen-based climate reconstruction (climate scenarios 1-5) (Mauri et al., 2015). In addition, a sixth scenario was added, representing the average mean annual temperature and mean annual precipitation combination for the period 12 cal kyr100 cal BP (Fig. 6). High-resolution time series were constructed using the same approach as for the application of the local peatland model.

To represent the land cover, five scenarios were constructed which consist of three land cover types (forest, grassland/short vegetation and cropland/bare soil) with varying cover fractions. The scenarios range from a fully forested landscape to an open landscape dominated by cropland (Table 1). As the scenarios are designed to cover the period $12 \mathrm{kyr}-100 \mathrm{BP}$ and widespread man-made structures are a rather recent phenomenon, built-up area is not included in the scenarios. Details on the allocation of the land cover types is described in Sect. A1.2 in the Appendix. This results in 30 possible climate-land cover scenario combinations. For 

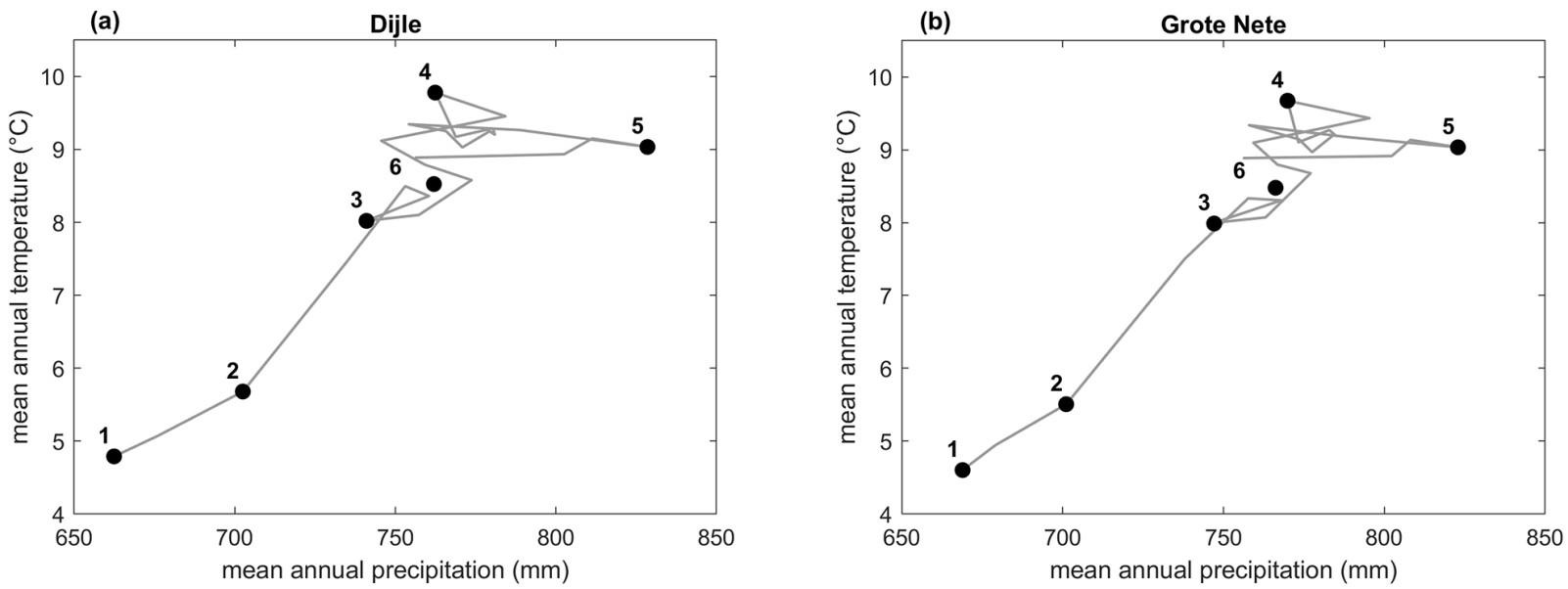

(c)

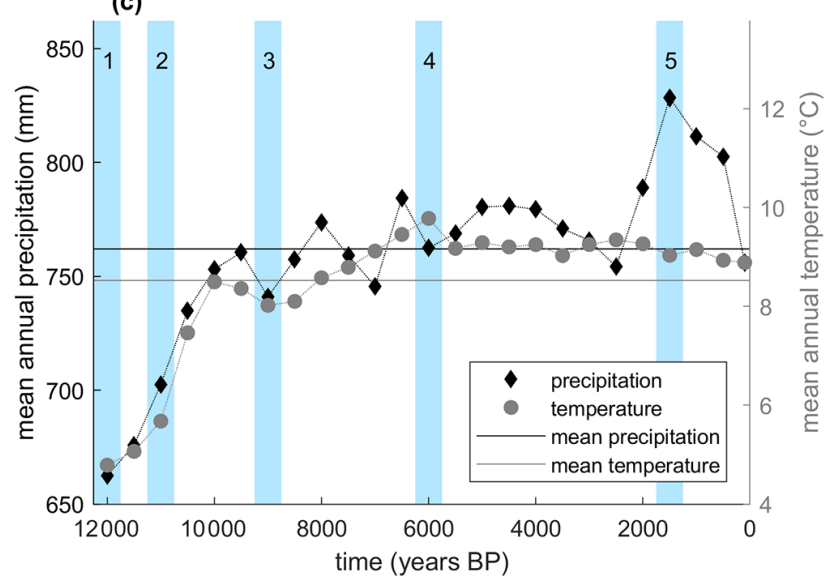

(d)

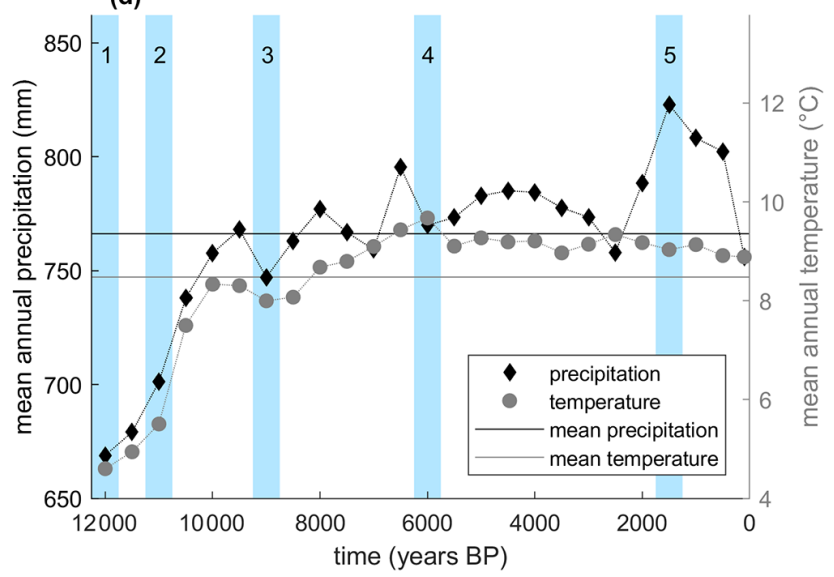

Figure 6. (a, b) Mean annual precipitation $(\mathrm{mm})$ and mean annual temperature $\left({ }^{\circ} \mathrm{C}\right)$ for each of the six climate scenarios for both the Dijle $(\mathbf{a})$ and Grote Nete (b) river basins. The grey line indicates the climate evolution ( 12 cal kyr-100 cal BP) according to the pollen-based climate reconstruction (Mauri et al., 2015). (c, d) Temporal evolution of the mean annual precipitation $(\mathrm{mm})$ and mean annual temperature $\left({ }^{\circ} \mathrm{C}\right)$ over the studied time period (12 kyr-100 BP) for the Dijle (c) and Grote Nete (d) river basins, according to the pollen-based climate reconstruction. The blue areas indicate the time periods corresponding to the conditions of climate scenarios $1-5$. The horizontal lines indicate the mean values over the studied period, which correspond to climate scenario 6 .

Table 1. Vegetation fractions (\%) for each of the five land cover scenarios.

\begin{tabular}{lrrr}
\hline Land cover scenario & Forest [\%] & Grassland/short vegetation [\%] & Cropland/bare soil [\%] \\
\hline Scenario 1 & 100 & 0 & 0 \\
Scenario 2 & 66.6 & 16.7 & 16.7 \\
Scenario 3 & 33.3 & 33.3 & 33.3 \\
Scenario 4 & 0 & 50 & 50 \\
Scenario 5 & 0 & 33.3 & 66.7 \\
\hline
\end{tabular}

each of these, STREAM was run for the Dijle and Grote Nete basins for a period of 100 years.

Whilst much research has been done on changing Holocene alluvial stratigraphies, the available information on river planform, river geometry and the position of the channel relative to the alluvial peat layer is limited for alluvial peatlands (Broothaerts et al., 2013; Candel et al., 2017; Lespez et al., 2015a; Nanson, 2009). As a result, it is not possible to identify a single spatial configuration for the model domain which can be assumed to be representative. Therefore, the coupled model is run to test the influence of channel morphology on alluvial peat growth. Firstly, different scenarios were constructed whereby the number of channels ranges between 1 and 25, thus simulating planforms ranging from 


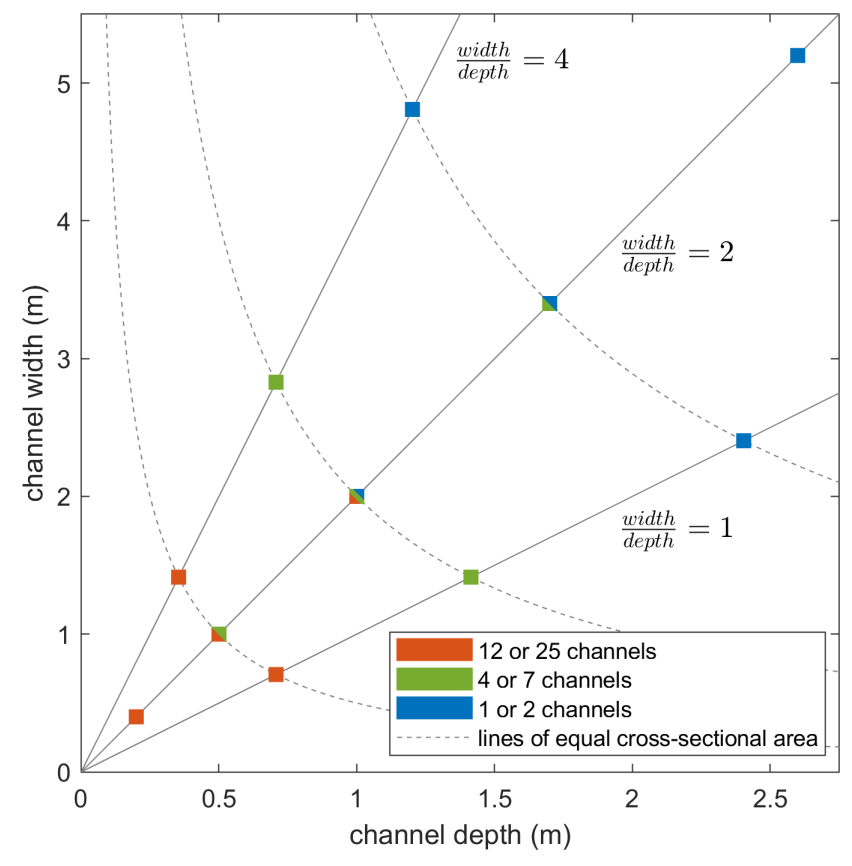

Figure 7. Channel width (m) and depth (m) for the different channel dimension scenarios. For each value for the number of channels, five possible channel dimension scenarios are used.

single-channel meandering to multi-channel anastomosing or anabranching wetland systems. Next, the scenarios for the channel dimensions were made dependent on the number of channels. This was done because it is unrealistic that a singlechannel river has a very small cross-sectional area (CSA) or that in a floodplain with a large number of channels, all will have a large cross-sectional area. As a result, for each number of channels, five possible channel dimensions were constructed, with an overall decrease in the cross-sectional area of each channel with an increasing number of channels (Fig. 7). All floodplain channels are assumed to be rectangular, with a specified width and depth. A study by Nanson et al. (2010) found a mean width / depth ratio of 2.2 for a set of alluvial-peatland channels, approximating the value of 2, which is the ratio for the most efficient water transport in rectangular channels without bedload. As a result, the dimension scenarios assume a width / depth ratio of 2 for three out of the five scenarios, with varying cross-sectional area (small, medium and large cross-sectional area). To test the effect of the width / depth ratio on the resultant peatland development, two additional scenarios are constructed with width / depth ratios of 1 and 4 with the same cross-sectional area as the middle scenario out of the three scenarios with a width / depth ratio of 2(Fig. 7).

Finally, not only a setting with the river incised in the substrate was tested, which is the standard situation for the climate and land use runs, but also a setting whereby the river channel is located in the peat layer itself, with the channel bottom at the level of the base of the peat column. The same scenario combinations as before were run for these two contrasting settings, with the difference being that the channel dimension scenarios for the second setting only take into account the width of the channel (Fig. 8). Over all scenario combinations, the simulated peat thickness ranges between 0.77 and $9.52 \mathrm{~m}$, with a mean value of $3.62 \mathrm{~m}$ for the Dijle River, and between 0.89 and $10.73 \mathrm{~m}$, with a mean value of $4.20 \mathrm{~m}$ for the Grote Nete River. The results indicate that especially the number of river channels strongly influences the peatland development, with a strong decrease in peat thickness with an increasing number of channels (Fig. 9).

When only considering all scenarios with four river channels, the effect of climate, land cover and channel dimensions on the peat thickness can be evaluated (Fig. 10). The peat thickness appears to be the highest under climate scenario 5, which has the highest mean annual precipitation amount, and lowest under climate scenario 4, which has the highest mean annual temperature (Fig. 10a). The different land cover scenarios do not result in significantly different peat thickness values (Fig. 10b). The dimensions of the river channels have a minor effect on the simulated thickness, with the highest values for channels with a small cross-sectional area and lower thickness values for channels with a larger crosssectional area. The three dimension scenarios with a medium cross-sectional area but with varying width/depth ratios show a small negative effect of increasing width / depth ratios on the resultant thickness (Fig. 10c).

Additionally, when comparing the two conceptual channel configuration scenarios, an overall increase in simulated peat thickness is observed for the simulations where the channels are located on top of the substrate, relative to those where the channel is situated in the substrate. The mean simulated peat thickness over all scenarios increases from 3.62 to $3.72 \mathrm{~m}$ for the Dijle River and from 4.20 to $4.30 \mathrm{~m}$ for the Grote Nete River.

\subsection{River channel properties}

Whilst STREAM determines the upstream hydrological boundary conditions in the alluvial setting, local hydrology is also determined by channel and floodplain properties such as the roughness and slope. For instance, lower roughness values and higher slopes will lead to a more efficient drainage of the alluvial wetlands, potentially leading to lower peat growth rates. In total, six roughness scenarios were constructed where both channel and floodplain roughness are varied together over $75 \%$ of the range found in the literature (Table 2). The floodplain slope is varied over $75 \%$ of the range in slopes observed across the Dijle and Grote Nete floodplains in five scenarios. The middle-of-the-road climate and land cover scenarios were used, which corresponds to climate scenario 6 and land cover scenario 3 .

The simulation results indicate a limited but positive effect of increasing channel and floodplain roughness on the resultant peat thickness (Fig. 11). Although the floodplain slope is 
(a)

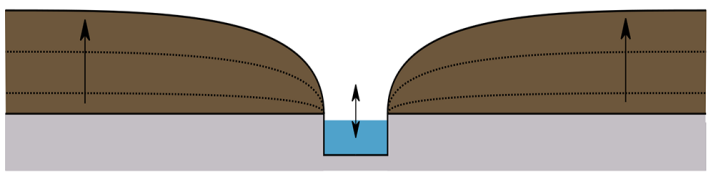

substrate (b)

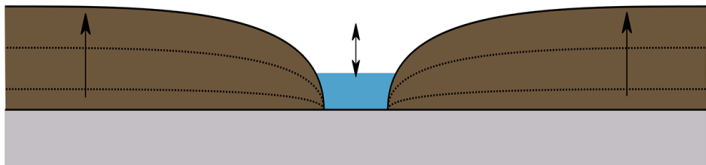

peat

Figure 8. Sketch of the two conceptual channel models used for the long-term peatland development simulations. (a) Rectangular channel, situated within the substrate, with the top of the channel corresponding to the base of the peat. (b) The channel located on top of the substrate, with the channel bottom corresponding to the base of the peat. The channel walls consist of the sloping sides of the peat bodies.
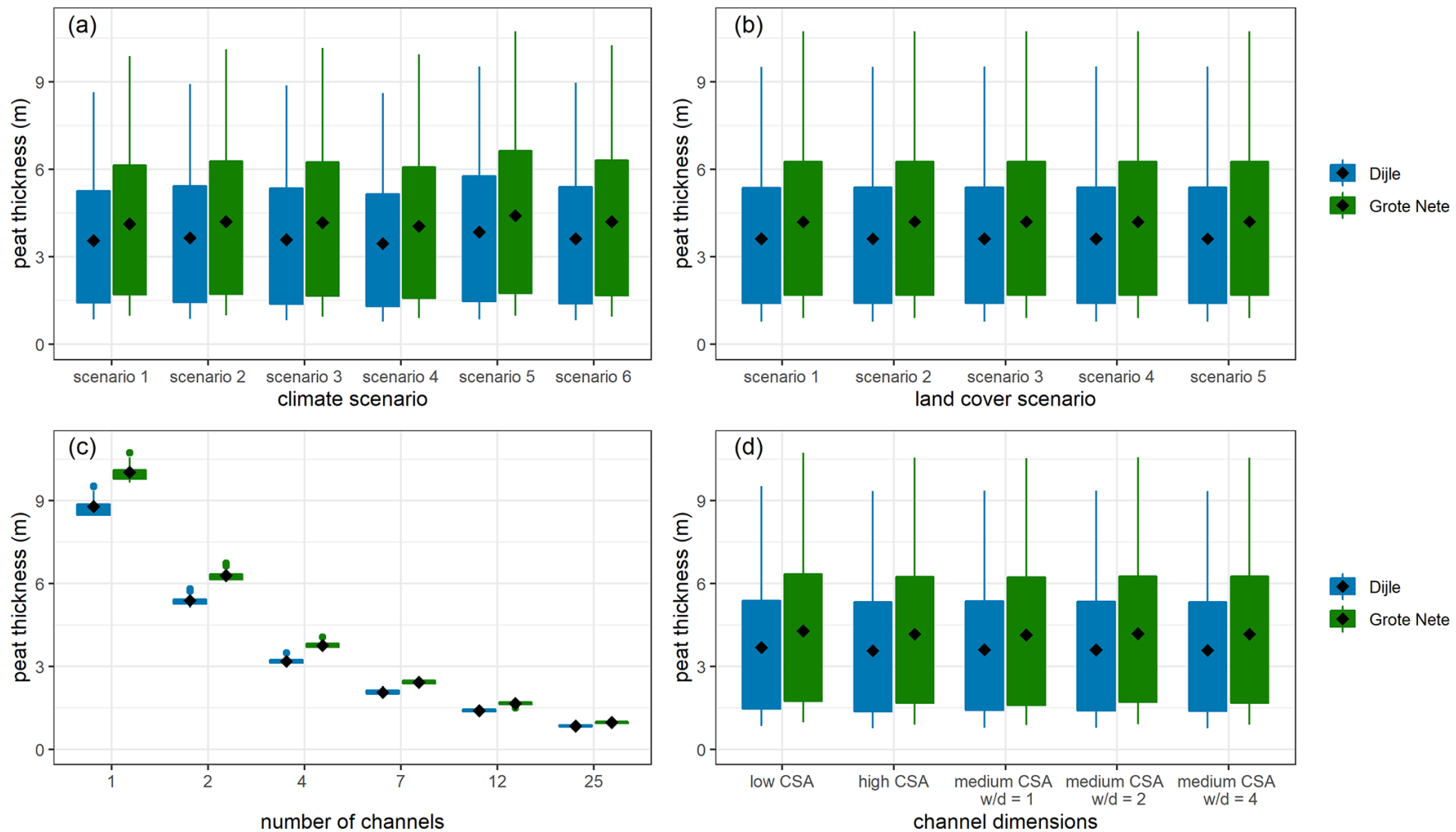

Figure 9. Boxplots of the simulated peat thickness (m) for all scenario combinations over a time period of 10000 years for the Dijle and Grote Nete rivers, subdivided per climate scenario (a), land cover scenario (b), number of channels (c) and channel dimensions (d). The mean value is indicated by a black diamond. The box indicates all values within the 25 th to 75 th percentile range, and the whiskers represent all values within the range from the 25 th percentile to 1.5 times the interquartile range to the 75 th percentile plus 1.5 times the interquartile range. Coloured dots represent all other values outside this range.

varied over an order of magnitude, the effect on the simulated peat thickness is also here rather limited.

\subsection{Vertical-channel aggradation}

In all previous model runs, the position of the river channel(s) was fixed in space, both in the lateral and vertical direction. While the detailed Holocene history of the channels in these river basins is not yet clear and requires specific reconstructions, the effect of vertically aggrading channels was simulated by increasing the channel bottom eleva- tion at a fixed rate. Here, the vertical aggradation rate of the channel was set to the mean Holocene peat accumulation rate, calculated as the mean Holocene peat thickness over the entire river basin divided by the duration of the Holocene (since 11.7 cal kyr BP). This results in an aggradation rate of $0.17 \mathrm{~mm} \mathrm{yr}^{-1}$ for the Dijle River and $0.05 \mathrm{~mm} \mathrm{yr}^{-1}$ for the Grote Nete River.

The results indicate a beneficial effect of vertically aggrading channels on the resultant peat thickness, with higher simulated thickness values for both the Grote Nete River and Dijle River (Fig. 12). The effect is more pronounced for the Di- 

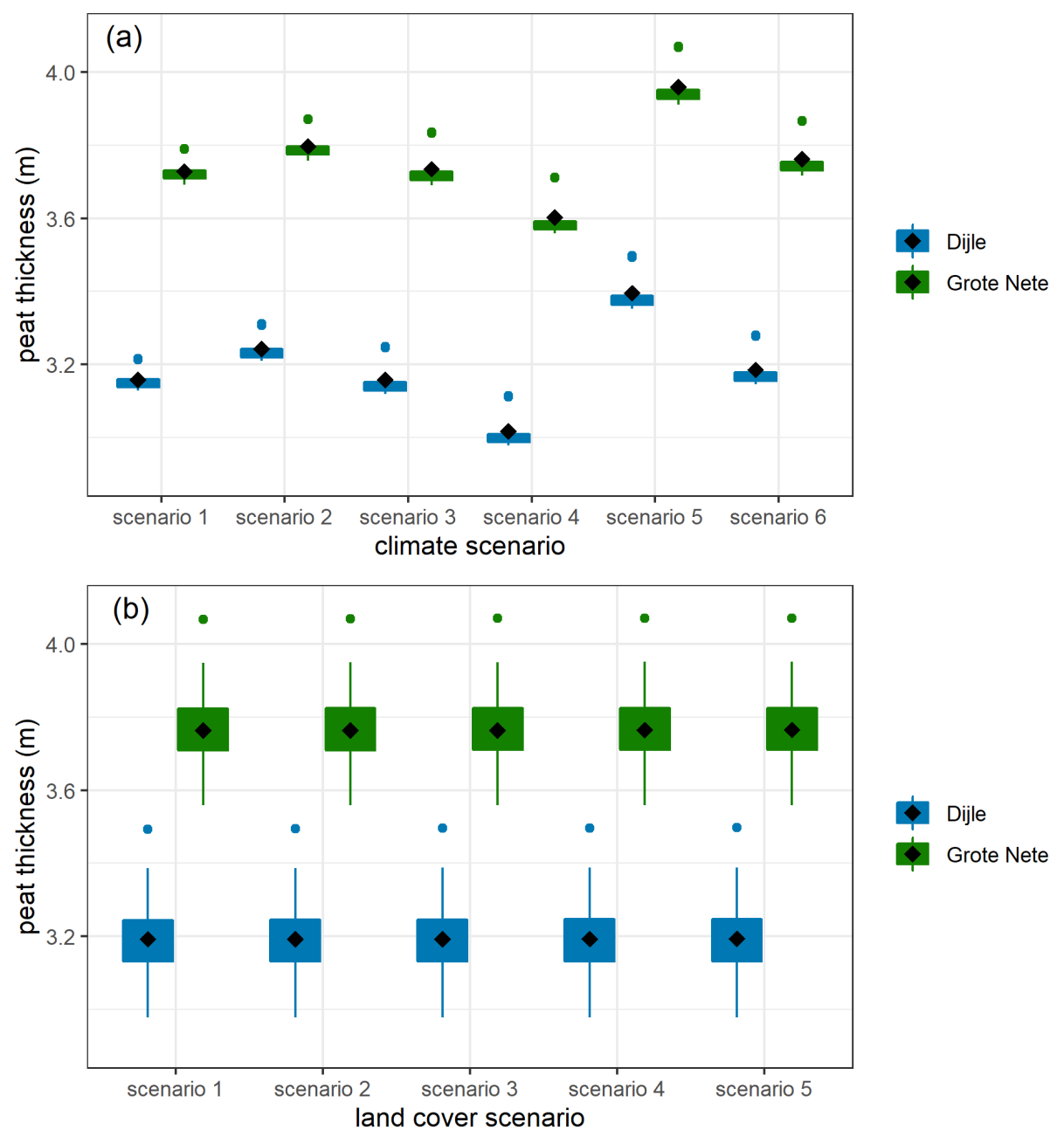

Dijle

Grote Nete

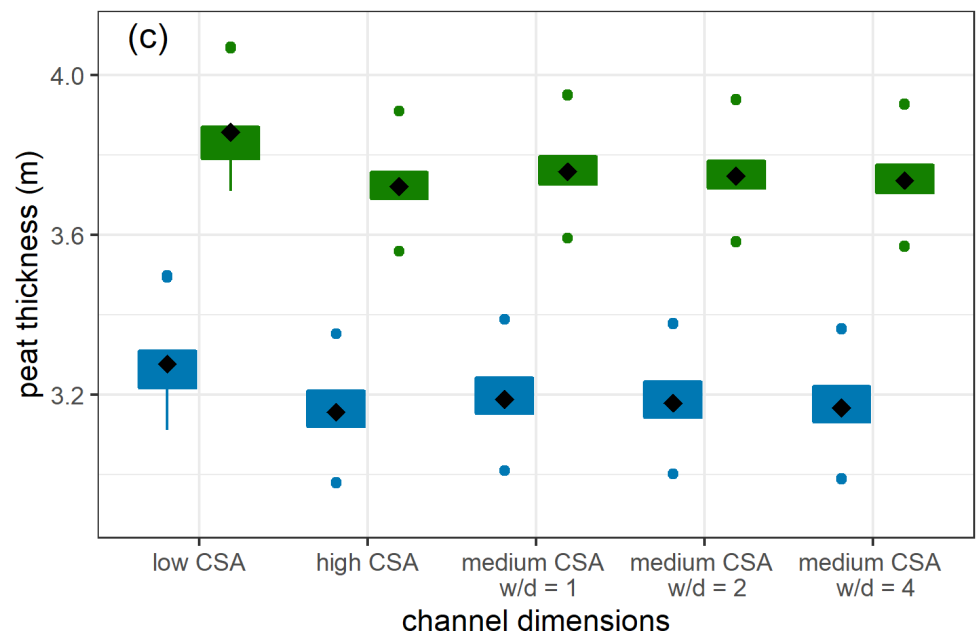

Dijle

Grote Nete

Figure 10. Boxplots of the simulated peat thickness $(\mathrm{m})$ for all scenario combinations with four river channels, over a time period of 10000 years for the Dijle and Grote Nete rivers, subdivided per climate scenario (a), land cover scenario (b) and channel dimensions (c). The mean value is indicated by a black diamond. The box indicates all values within the 25 th to 75 th percentile range, and the whiskers represent all values within the range from the 25 th percentile to 1.5 times the interquartile range to the 75 th percentile plus 1.5 times the interquartile range. Coloured dots represent all other values outside this range. 
Table 2. Range over which the channel and floodplain roughness $\left(\mathrm{sm}^{-1 / 3}\right)$ and the channel/floodplain slope $\left(\mathrm{mm}^{-1}\right)$ are varied in the scenario analysis.

\begin{tabular}{lrrl}
\hline Parameter & Minimum value & Maximum value & References \\
\hline Channel roughness & 0.02 & 0.07 & $\begin{array}{l}\text { Hosia (1980); Lappalainen et al. (2010); Marttila et al. (2012); } \\
\text { Tuukkanen et al. (2012) }\end{array}$ \\
& 0.035 & 0.15 & $\begin{array}{l}\text { Medeiros et al. (2012b); Thomas and Nisbet (2007) } \\
\text { Floodplain roughness }\end{array}$ \\
Channel/floodplain slope & $2.5 \times 10^{-4}$ & $2.5 \times 10^{-3}$ & $/$ \\
\hline
\end{tabular}
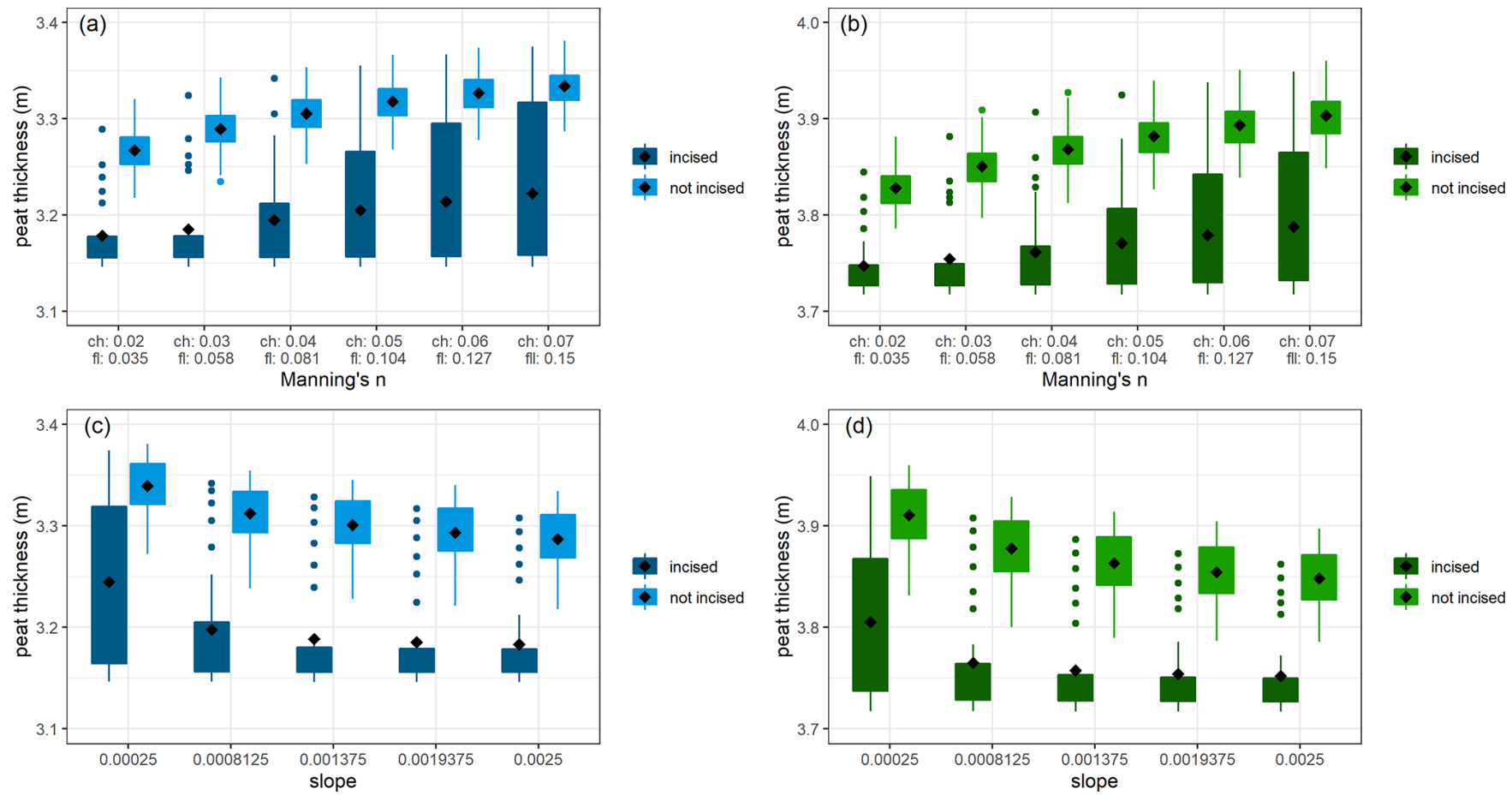

Figure 11. Boxplots of the simulated peat thickness (m) after 10000 years of simulation for the Dijle (a, c) and Grote Nete (b,d) rivers for the different scenarios of channel (ch) and floodplain (fl) roughness coefficients (a, b) and the floodplain and channel slope (c, d) for a floodplain setting with four channels and for the five possible channel dimension scenarios. Each plot divides the results between the scenarios with a rectangular channel incised in the substrate and the scenarios without an incised channel. The mean value is indicated by a black diamond. The box indicates all values within the 25 th to 75 th percentile range, and the whiskers represent all values within the range from the 25 th percentile to 1.5 times the interquartile range to the 75 th percentile plus 1.5 times the interquartile range. Coloured dots represent all other values outside this range.

jle River due to the higher aggradation rate and mostly affects the scenarios with a high number of channels. For the Dijle River in a setting with one river channel, the mean simulated peat thickness increases by $1.17 \mathrm{~m}$ from 8.79 to $9.96 \mathrm{~m}$. For a setting with 25 channels, the mean thickness increases by $1.66 \mathrm{~m}$ from 0.86 to $2.51 \mathrm{~m}$.

\section{Discussion}

A new modelling framework was presented to simulate the development of alluvial peatlands over Holocene timescales by coupling a local peat growth model with a river basin hydrology model. The 1D DigiBog model was modified to better represent peat growth in floodplain environments. In a first step, the modified DigiBog model was used to simulate the Holocene development of the alluvial peatlands for the two contrasting study areas, excluding the effect of the river basin hydrology. The results show a rapid peatland development in accordance with increasing temperatures and precipitation amounts during the early Holocene, stabilizing from approximately $6000 \mathrm{BCE}$ onwards. The simulated development trajectories match relatively well with the field data in terms of the timing of peatland development. The peat growth between 10.05 and $6.05 \mathrm{kyrBCE}$ in the Belgian river valleys corresponds with reconstructed surface peat index curves, which indicate a strong increase in the floodplain 

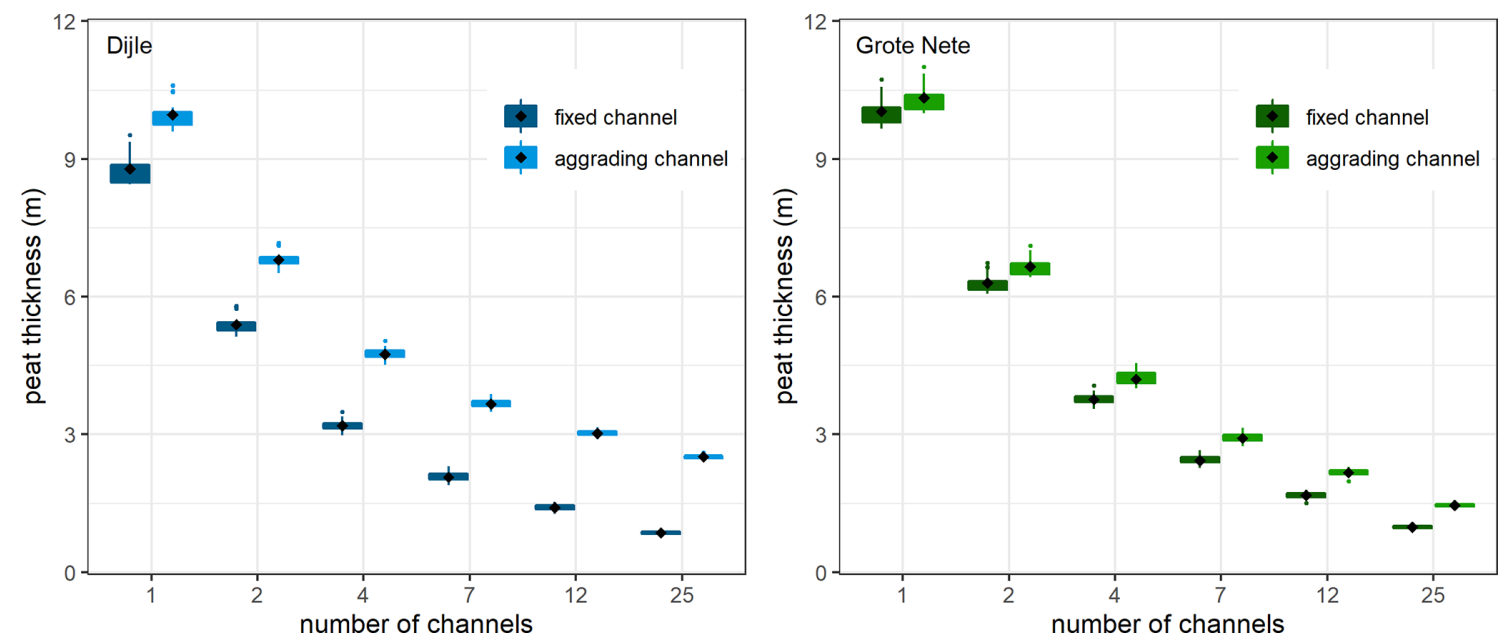

Figure 12. Boxplots of the simulated peat thickness (m) over all scenario combinations after 10000 years of simulation for the Dijle and Grote Nete rivers for different numbers of channels. The simulations assume channels with a fixed position in the substrate (fixed channel) or channels which aggrade vertically at a fixed rate (aggrading channel). The mean value is indicated by a black diamond. The box indicates all values within the 25 th to 75 th percentile range, and the whiskers represent all values within the range from the 25 th percentile to 1.5 times the interquartile range to the 75 th percentile plus 1.5 times the interquartile range. Coloured dots represent all other values outside this range.

area under active peat growth until 8 cal kyr BP, especially for the rivers in the loess belt (Swinnen et al., 2020). However, the simulations show a rather similar Holocene trajectory for the Dijle and Grote Nete rivers, with only minor differences in terms of peat thickness and the timing of changes, which does not correspond with the available data on floodplain stratigraphy (Fig. 5). The high degree of similarity between both areas can be attributed to the modelling assumptions. As only the local peat growth model is used, the potential differences due to processes at the basin scale or in the local river network cannot be simulated. As such, these results show that a model setup which only simulates the internal dynamics of alluvial peatlands and that does not incorporate external factors such as seepage, river channel dynamics and river basin hydrology seems to be unable to reconstruct the observed differences in alluvial-peatland dynamics between the loess and sand belts.

\subsection{Factors controlling alluvial-peatland dynamics}

Sensitivity analysis was used to determine the effect of individual model parameters on the resultant peatland dynamics to identify important processes controlling the long-term dynamics of alluvial peatlands. One of the important changes to the original DigiBog model is the incorporation of a wider variety of vegetation types. Most long-term peatland models use empirical equations which relate the productivity to one or more hydrological or vegetation parameters such as the actual evapotranspiration rate or the water table depth. However, the limited data availability at Holocene timescales and corresponding simplicity of these equations results in a trial-and-error procedure of selecting the most appropriate productivity equation. As such, the productivity equation used here has been applied across the globe and allows for a wide variety of vegetation types (Lieth, 1973; Lieth and Box, 1972). While this approach might be less precise than more detailed equations, the results of the sensitivity analysis indicate that the model parameters related to the peatland vegetation have a limited effect on the resultant peat thickness. Contrary to local floodplain vegetation, physical properties of peat including the dry bulk density and the hydraulic conductivity do show to have a strong impact on final peat thickness (Fig. 4). In addition, several model parameters related to the local hydrological setting such as precipitation, spacing between the channels and vertical groundwater flux are also shown to be very influential. This demonstrates the importance of detailed environmental reconstructions of past conditions and the need for a correct representation of the hydrological interaction between the alluvial peat layer and its surroundings. Although a detailed calibration and validation procedure was not possible for the peat growth model, the results of the sensitivity analysis can be compared to compaction-corrected peat thickness values for both river basins, derived from a dataset of soil coring data (Swinnen et al., 2020). The range in peat thickness values simulated in the sensitivity analysis $(0.4-5.61 \mathrm{~m})$ matches more or less with the reconstructed uncompacted peat thickness data $(0.1-6.7 \mathrm{~m})$ for the different river valleys. The results of the scenario-based simulations demonstrate that changes in the river discharge, which are related to climatic and land cover changes, have a limited effect on the alluvial-peatland development (Figs. 9 and 10). This can be attributed to the fact that climate and land cover changes mostly affect the magnitude of peak events rather than the mean discharge. As peak flows are relatively rare by nature, their effect on the 
peatland water table and thus on the thickness of the peat layer is rather limited. In addition to the hydrological effect, changes in climate or land cover over the upstream basin will also affect other aspects such as landscape sediment dynamics, river channel stability and groundwater-peatland interactions, which are not simulated here.

\section{River channel dynamics}

Overall, the results of the scenario analysis indicate that the characteristics related to the position of river channel(s) are the most influential, especially the number of channels in a floodplain cross section (Figs. 9 and 12). A higher number of channels in the same floodplain cross section increases the slope of the water table between the centre of the peat body and the river channel, resulting in increased drainage efficiency and lower simulated peat thickness values. Both the OAT analysis and scenario-based simulations demonstrate the important effect of model parameters related to the local river network properties on the simulated peat thickness. Especially for settings with multiple river channels, the simulated peat thickness is more in line with the mean measured peat thickness of $1.60 \mathrm{~m}$ for the Dijle River and $0.56 \mathrm{~m}$ for the Grote Nete River. These results suggest that the early Holocene river network in both the Grote Nete River and Dijle River basins did not consist of a singlechannel situation as is the case in current time periods but rather an anastomosing pattern with multiple active channels and peat growth on the islands in between. The formation of an anastomosing pattern can be explained by the low floodplain gradients in both the Dijle River and Grote Nete River basins and the erosion resistance of peat layers. In such a river system, the formation of new channels is triggered by avulsions, which can be caused by obstructions such as log jams or beaver dams (Diefenderfer and Montgomery, 2009; Gradziński et al., 2003; Makaske, 2001; Polvi and Wohl, 2012; Stefan and Klein, 2004). The setting of alluvial peatlands with an anastomosing river network has been described in other studies across the European lowlands (Broothaerts et al., 2014a; Gradziński et al., 2003; Lespez et al., 2015b). On the other hand, Candel et al. describe a different floodplain development trajectory for a peat-filled lowland stream (Drentsche Aa) where the difference in erosion resistance of the peat and the valley sides result in oblique aggradation and highly sinuous single-channel planforms (Candel et al., 2017). However, floodplains of the Drentsche Aa contain peat layers of up to $7 \mathrm{~m}$ thick, which is much more than the thicknesses measured for the Dijle and Grote Nete rivers. This combination of a single-channel setting and high peat thickness values for the Drentsche Aa corresponds with the model simulations in this study assuming a limited number of channels and vertical-channel aggradation (Fig. 12). These results seem to suggest that the overall peat thickness can provide a rough estimate of the typical floodplain drainage pattern. However, which factors determine the presence of a single-channel or anastomosing pattern in peat-filled valleys is unclear. The amount of available studies is rather limited and does not allow us to identify which setting was more common in the European lowlands throughout the Holocene.

The two conceptual channel configurations which are applied here determine the effect of the channel hydrograph on the peatland water table (Fig. 11). When considering an incised channel, only discharge events above bankfull discharge will influence the drainage in the peat layer, given the assumption of an impermeable substrate below the peat. If the channel is situated on top of the substrate, all water level variations inside the channel will influence the water level in the peat layer. Overall, the results indicate a modest increase in the simulated peat thickness for the configuration where the channel is located on top of the substrate, relative to an incised channel. In addition, other parameters representing channel properties such as the channel roughness and slope have a limited effect on the simulated peat thickness compared to other model parameters. Vertical aggradation on the other hand has a much more profound impact on the resulting peat thickness, especially for the scenarios with multiple channels, suggesting that channel mobility rather than channel properties impact peat growth (Fig. 12). However, these scenarios assume a vertically aggrading channel without geomorphic interaction between the peatland and the river channel. While peat is rather cohesive and thus limits channel mobility, it is unclear how realistic this assumption is over long timescales. Overall, the model simulations suggest that alluvial-peatland development is strongly determined by the spatial organization of the river channels across the river floodplain and the vertical-channel mobility over longer timescales. As such, a good understanding of the geomorphic and hydrologic interactions between the river network and the alluvial peatlands is required to make detailed simulations of past and future alluvial-peatland dynamics.

\section{Conclusions}

In this study, a new model was presented which is specifically designed to simulate alluvial-peatland development over Holocene timescales in relation to changes in both local and regional environmental conditions. A scenario-based approach was used to assess the sensitivity of alluvial peat growth to environmental changes under a wide range of settings. Although the simulations are explorative, the results demonstrate that the approach used here can improve our understanding of the different interactions and feedbacks between alluvial peatlands and the river network. Overall, the alluvial-peatland dynamics appear to be strongly determined by the setting and dynamics of the local river network, rather than by internal peatland dynamics or regional environmental changes. The scenario analysis suggests that a floodplain setting with an anastomosing river pattern and peat formation on the islands in between the channels matches best with the 
observed peat thickness in the studied river basins in the European loess and sand belts. In general, these results highlight the need for detailed reconstructions of Holocene floodplain and river channel dynamics, which are required for a detailed understanding of past and future peatland dynamics in alluvial environments.

\section{Appendix A}

\section{A1 STREAM water balance model}

STREAM is a grid-based water balance model which simulates the hydrological cycle of a river basin using a set of spatially explicit reservoirs and fluxes (Fig. A1). A detailed discussion of the model features is given by Ward et al. (2007). Here, the modifications to the original model layout, the input data and the calibration procedure are discussed.

While STREAM is a spatial model, the produced runoff is not explicitly routed through the landscape but is assumed to accumulate according to the steepest-descent principle and reach the river basin outlet during the same time step. Given the relatively short time step of $1 \mathrm{~d}$ used in this study, this assumption results in very high peak discharge values during rainfall events. Here, the travel time between each grid cell and the basin outlet was calculated by defining the downstream distance to the nearest stream and the in-stream distance to the outlet of the basin. By selecting specific values for the velocity of both overland runoff $\left(0.3 \mathrm{~m} \mathrm{~s}^{-1}\right)$ and channel flow $\left(0.45 \mathrm{~m} \mathrm{~s}^{-1}\right)$, the time necessary for runoff to reach the basin outlet could be calculated for each location. The assumption was made that all precipitation falls in the middle of each time step. As a result, for each grid cell, it can be calculated during which time step the overland flow reaches the outlet, based on the travel time. This results in an attenuation of the peak discharge, with runoff generated further upstream in the basin being added to the basin hydrograph in later time steps.

\section{A1.1 STREAM calibration}

In total, STREAM contains three calibration parameters which allow us to fine-tune the model behaviour. The evapotranspiration parameter $\left(P_{\text {cal }}\right)$ calibrates the amount of evapotranspiration and thus controls the balance between the basin precipitation and the river flow at the basin outlet. The other two calibration parameters ( $S_{\text {cal }}$ and $\left.G_{\text {cal }}\right)$ determine the relationship between the amount of water present in the soil and groundwater reservoirs and their contributions to the basin discharge. The model is calibrated for both the Dijle and Grote Nete basins at a spatial resolution of $50 \mathrm{~m}$ by comparing the simulated daily discharge time series with the observed discharge at the location of available gauging stations. In this case, the gauging stations of the Flemish Environmental Agency (VMM) in Sint-Joris-Weert (Dijle) and Hulshout (Grote Nete) are used (Fig. A2 and Table A1). Simu- lations are performed for the period for which observed discharge time series are available, extended with a 2-year spinup phase to allow the different water reservoirs in STREAM to fill up. All three calibration parameters are varied stepwise, and the evaluation of the best fitting parameter combination is based on the Nash-Sutcliffe model efficiency (Nash and Sutcliffe, 1970).

In the model simulations, it is assumed that all discharge produced by the river basin passes through the channel at the outlet of the basin. This assumption can be made for the observed time series as well, except when the measured discharge exceeds the bankfull stage, which is the upper limit for the observed discharge time series. As a result, the calibration process excludes the time steps in which the modelled values exceed the bankfull discharge value at the gauging station location, since the observed value will never exceed this threshold by nature. The calibration simulations span the period 1977-2017 for the Dijle River and 19852017 for the Grote Nete River. The climate time series (mean daily temperature and daily precipitation) are derived from weather stations of the Belgian Royal Meteorological Institute (KMI) for stations in and around the river basins. These point data are converted to rainfall and temperature maps using Thiessen polygons (Fig. A2 and Table A1).

In addition, the model requires data on soil type, topography and land cover. Topographic information is derived from the SRTM (Shuttle Radar Topography Mission) 1 ArcSecond Global version 3 dataset. Land cover information is derived from the $100 \mathrm{~m}$ spatial resolution CORINE (Coordination of Information on the Environment) land cover maps of 1990, 2000, 2006 and 2012, which are simplified to five land cover classes (Table A2) (EEA, 1995). The land cover at a certain time step is assumed to be equal to one of the four land cover maps, situated closest in time. The hydrological properties of the soil are derived from the European Soil Hydraulic Database (EU-SoilHydroGrids). This database provides a wide variety of hydrological properties at seven distinct depths in the upper $2.5 \mathrm{~m}$ of the soil profile with a spatial resolution of $250 \mathrm{~m}$ (Tóth et al., 2017). The field capacity, wilting point and water-holding capacity used in this study are calculated as an integration from the soil surface to a depth of $2.5 \mathrm{~m}$. For each of the simplified land cover classes, a specific land cover coefficient value (CROPF) is used, which is based on independent evapotranspiration data (Table A2) (Gellens-Meulenberghs and Gellens, 1992; Notebaert et al., 2011). All maps are resampled to a $50 \mathrm{~m}$ resolution using bilinear interpolation.

To calculate the amount of overland flow during rainfall events, curve numbers were assigned to each unique combination of the simplified land cover classes and hydrological soil groups (Soil Conservation Service, 1986; Suphunvorranop, 1985). The texture classes of the Belgian soil map are reclassified into five hydrological soil groups (Table A3). For locations in the landscape for which the soil texture was not identified, the dominant hydrological soil group in the river 


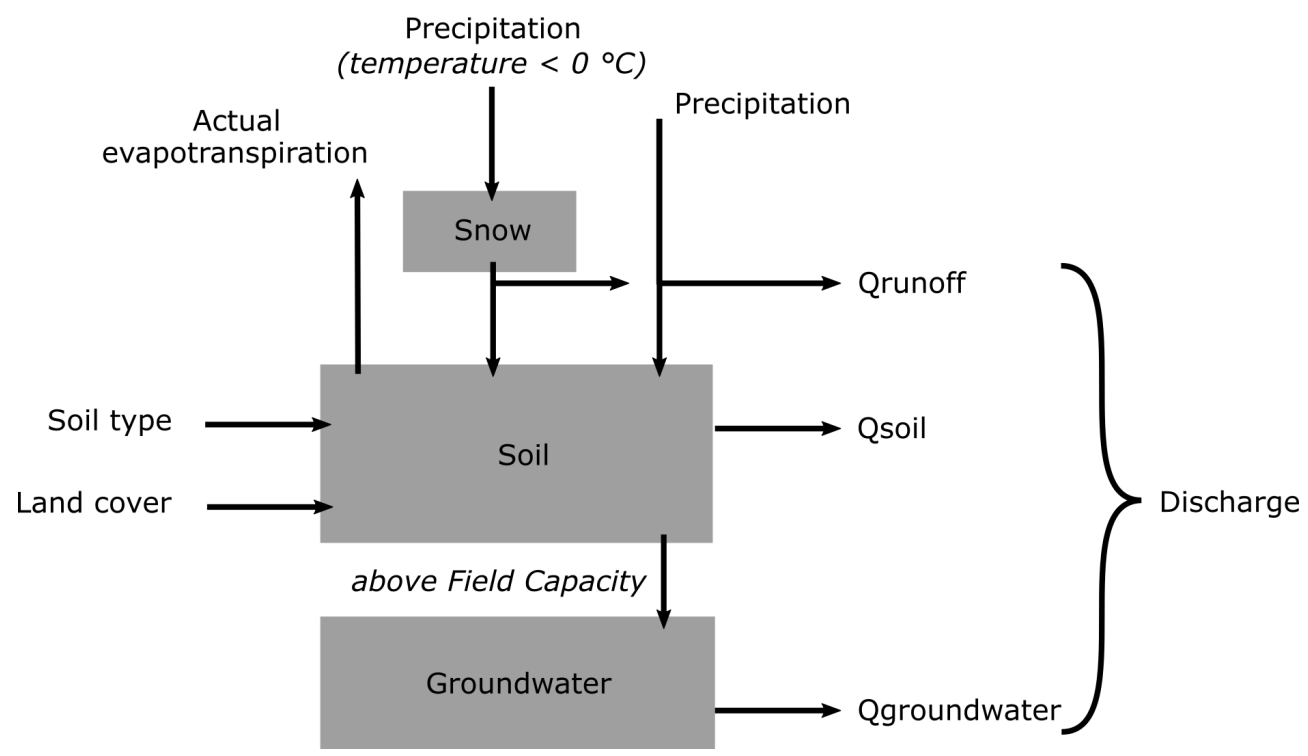

Figure A1. Schematic structure of the STREAM water balance model (based on Aerts et al., 1999).

Table A1. List of the hydrological and meteorological stations used for the calibration of STREAM for the Dijle River and Grote Nete River basins. KMI: Belgian Royal Meteorological Institute.

\begin{tabular}{lllll}
\hline River basin & Calibration period & Hydrological station & $\begin{array}{l}\text { Meteorological stations used } \\
\text { for precipitation data }\end{array}$ & $\begin{array}{l}\text { Meteorological stations used } \\
\text { for temperature data }\end{array}$ \\
\hline Dijle & $1973-2017$ & Sint-Joris-Weert (L08_098) & $\begin{array}{l}\text { Beauvechain (KMI) } \\
\text { Braine-l'Alleud (KMI) }\end{array}$ & Ukkel (KMI) \\
& & & Chastre (KMI) & \\
& & & Marbais (KMI) & \\
& & & Ukkel (KMI) & \\
& & & Zaventem (KMI) & \\
\hline Grote Nete & $1985-2017$ & Hulshout (gnt05a-1066) & Kleine-Brogel (KMI) & Kleine-Brogel (KMI) \\
& & & Lommel (KMI) & Zaventem (KMI) \\
& & & Diest (KMI) &
\end{tabular}

basin was assumed. As most open waters in both river basins are artificial and often used for rainwater buffering, they are not assumed to contribute to the basin runoff and thus have a curve number value of 0 .

The calibration procedure resulted in a model efficiency of 0.348 for the Dijle River and 0.422 for the Grote Nete for the daily discharge time series (Table A4). Overall, the calibrated model versions are able to reproduce the mean discharge over the calibration period relatively well with a simulated and observed mean discharge of 4.90 and $4.83 \mathrm{~m}^{3} \mathrm{~s}^{-1}$ for the Dijle River and 5.01 and $4.87 \mathrm{~m}^{3} \mathrm{~s}^{-1}$ for the Grote Nete River. Overall, significant differences occur between the observed and simulated discharge time series with mean relative error values of $23.1 \%$ for the Dijle River and $38.1 \%$ for the Grote Nete River.

Overall, the model efficiency for the best-fitting parameter combination is rather limited, especially for the Dijle basin, which also results in high mean relative errors (Table A4). It is however difficult to set a threshold value for the Nash-Sutcliffe model efficiency to determine when the model performance is sufficient, since that value is highly dependent on the model application (Beven, 2006). A model efficiency above 0 should be taken as a minimum, since it indicates that the model predicts better than the mean value over the entire time series. In the literature, model efficiency values between 0.36 and 0.8 are mentioned as threshold values for acceptable model performance for various hydrological models and spatial and temporal scales (Knoben et al., 2019; Moriasi et al., 2007; Ritter and Muñoz-Carpena, 2013). The model efficiency values obtained here for the Dijle and Grote Nete rivers fall within the lower part of this range (Table A4). However, the use of a model with three reservoirs limits the hydrology to a quick (runoff), intermediate (soil throughflow) and slow (groundwater flow) response to pre- 


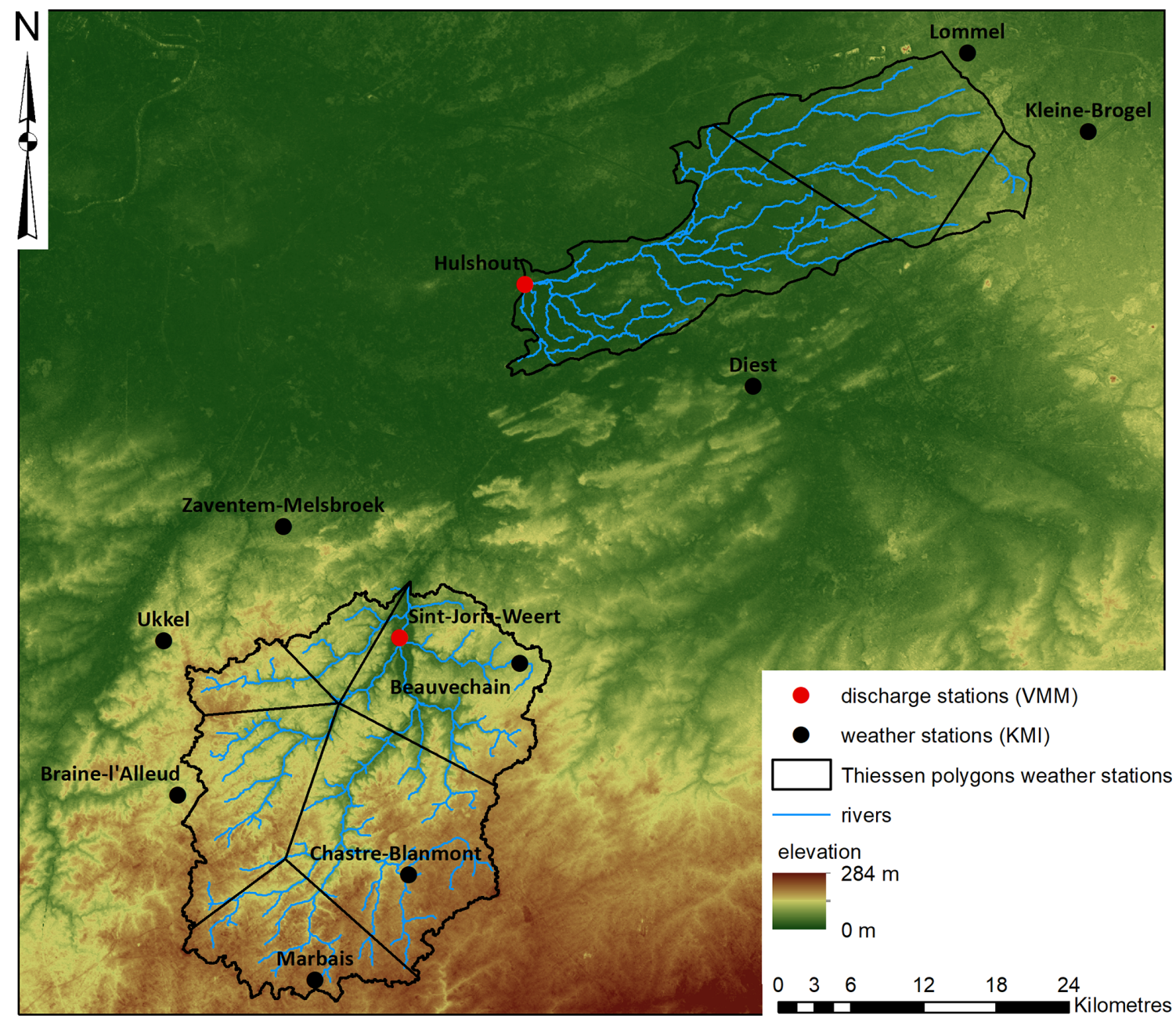

Figure A2. Map of the Dijle and Grote Nete basins, with indications of the discharge measuring stations (Flemish Environmental Agency, VMM) and weather stations (Belgian Royal Meteorological Institute, KMI) used for the calibration of STREAM. The river basins are subdivided by Thiessen polygons, based on the location of the weather stations.

cipitation events, which are determined by the calibrated coefficients, limiting the freedom of the model. Additionally, the calibration procedure is based on the simulated and measured discharge time series. However, the measuring stations on the Dijle and Grote Nete rivers, operated by the VMM do not measure river discharge directly. Water stages are recorded and converted to discharges using empirical equations, which are updated once every few years. Given the use of a single conversion equation under varying conditions regarding channel vegetation and a changing cross-sectional area, it can be expected that the discharge value reported by the VMM deviates from the true river discharge. The effect of this error on the calibration procedure is difficult to quantify, and as such, the discharge time series as provided by the VMM are assumed to be representative.

\section{A1.2 STREAM simulations for scenario analysis}

To simulate the basin discharge under different climate and land cover scenarios, the land cover fractions must be allocated to provide land cover maps. However, it is unclear to what extent the spatial arrangement of the different land cover classes impacts the resulting basin hydrograph. A recent study on the Dijle River used both pollen-based vegetation reconstructions and sediment delivery modelling to come up with realistic land cover maps for six archaeological periods (Neolithic period, Bronze Age, Iron Age, Roman age, early medieval period and late medieval period). A total of almost 63000 land cover maps were produced with vegetation fractions matching the pollen-based reconstructions but with varying land cover patterns. For each land cover map, the annual hillslope sediment delivery was modelled using the WaTEM/SEDEM (Water and Tillage Erosion Model and Sediment Delivery Model) model. By comparing the 

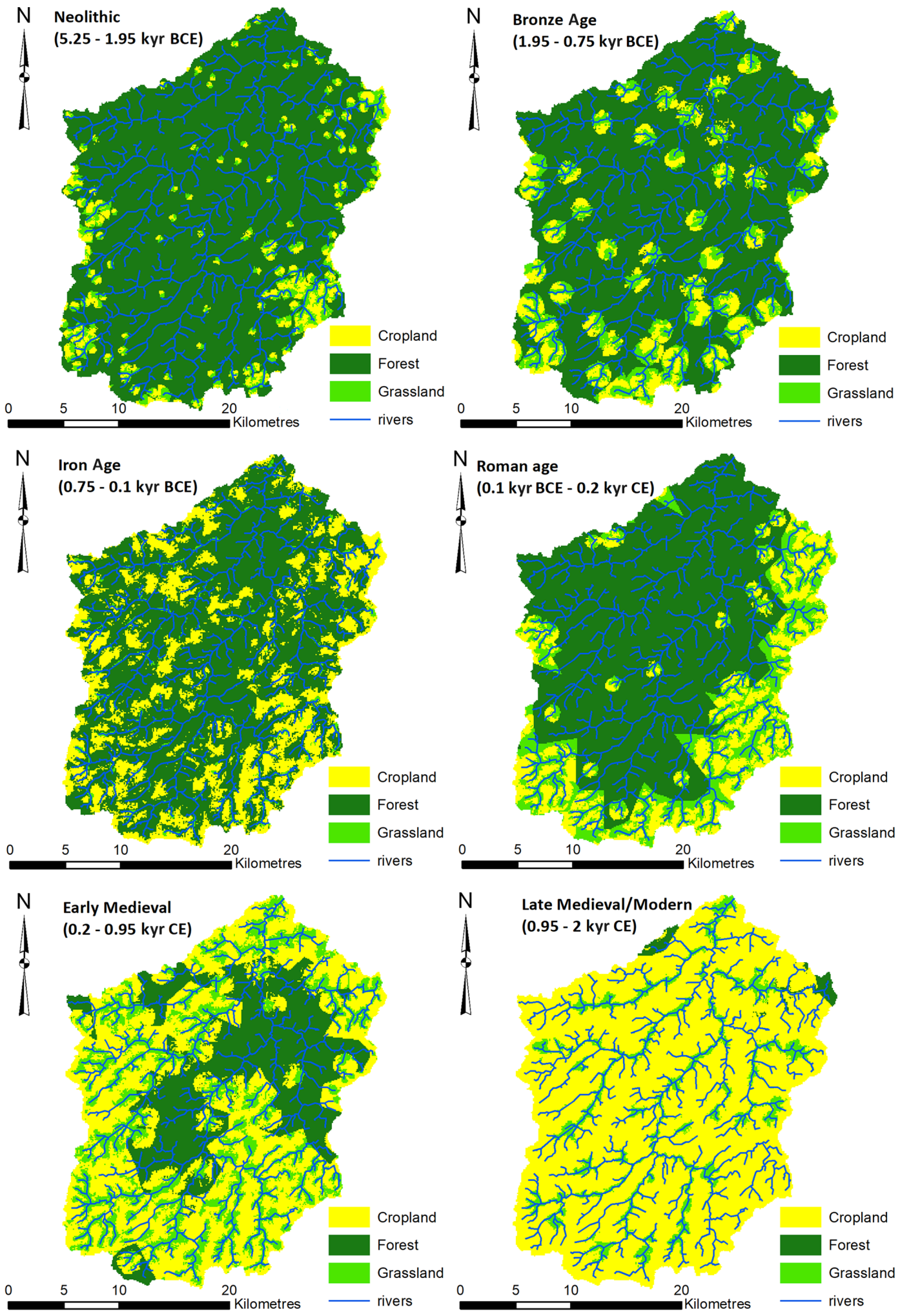

Figure A3. Land cover maps for six archaeological periods (Neolithic period, Bronze Age, Iron Age, Roman age, early medieval period and late medieval period-modern period), matching best the reconstructed pollen-based vegetation fractions and floodplain sediment delivery model for the Dijle basin. 
Table A2. Reclassification of the CORINE land cover classes used in the hydrological simulations and land cover coefficient values (CROPF) for the simplified land cover classes, used in the evapotranspiration calculations.

\begin{tabular}{|c|c|c|c|}
\hline New land cover class & CROPF value & CORINE code & CORINE land cover class \\
\hline \multirow[t]{4}{*}{ Built-up area } & 0.995 & 111 & Continuous urban fabric \\
\hline & & 112 & Discontinuous urban fabric \\
\hline & & 121 & Industrial or commercial units \\
\hline & & 122 & Road and rail networks and associated land \\
\hline \multirow[t]{6}{*}{ Arable land/bare soil } & 1.013 & 131 & Mineral extraction sites \\
\hline & & 132 & Dump sites \\
\hline & & 133 & Construction sites \\
\hline & & 211 & Non-irrigated arable land \\
\hline & & 331 & Beaches, dunes, sands \\
\hline & & 333 & Sparsely vegetated areas \\
\hline \multirow[t]{9}{*}{ Pasture/grassland } & 1.013 & 124 & Airports \\
\hline & & 142 & Sport and leisure facilities \\
\hline & & 222 & Fruit trees and berry plantations \\
\hline & & 231 & Pastures \\
\hline & & 242 & Complex cultivation patterns \\
\hline & & 243 & $\begin{array}{l}\text { Land principally occupied by agriculture, with } \\
\text { significant areas of natural vegetation }\end{array}$ \\
\hline & & 321 & Natural grasslands \\
\hline & & 322 & Moors and heathlands \\
\hline & & 412 & Raised bogs \\
\hline \multirow[t]{5}{*}{ Forest } & 1.129 & 141 & Green urban areas \\
\hline & & 311 & Broad-leaved forest \\
\hline & & 312 & Coniferous forest \\
\hline & & 313 & Mixed forest \\
\hline & & 324 & Transitional woodland-shrub \\
\hline \multirow[t]{3}{*}{ Open water } & 1.266 & 411 & Inland marshes \\
\hline & & 511 & Water courses \\
\hline & & 512 & Water bodies \\
\hline
\end{tabular}

model output with the reconstructed geomorphic record for the Dijle River, land cover patterns with unrealistic sediment dynamics could be ruled out (De Brue, 2016). Here, for each archaeological period studied by De Brue, the land cover pattern was selected which best matches both the pollen-based vegetation and the geomorphic sediment delivery reconstructions (Fig. A3 and Table A5). These land cover maps can be assumed to be realistic patterns for each of the archaeological periods. For each of these six periods, two hydrological simulations were run using the calibrated STREAM model for the Dijle basin over a period of 100 years: one with a realistic land cover pattern and one with a land cover map consisting of identical vegetation fractions but with random allocation. To rule out any climate effects, for all periods the simulations were run with the same climate scenario, namely the mean conditions for the Holocene. Differences between the two simulated hydrographs at the outlet of the basin can be used to identify the effect of land cover allocation on the hydrological simulations.
The results indicate that the effect of the land cover allocation on the simulated discharges is rather small, as reflected in the high values for the coefficients of determination (Fig. A4). However, for the archaeological periods in which the land cover is dominated by one land cover type, such as forest for the Neolithic period or cropland for the late medieval-modern period, the difference between realistic and random allocation is clearly smaller than for periods during which the land cover was more diversified such as during the Iron Age and Roman age. Given these results, the land cover in the scenario analysis was allocated randomly.

\section{A1.3 Applying STREAM to the Dijle River and Grote Nete River basins}

The river basin hydrology was simulated over a period of 100 years for the Dijle and Grote Nete basins for each combination of the climate and land cover scenarios. The differences between the two contrasting river basins are for most hydrological fluxes larger than the range over all scenario combinations, demonstrating that the inherent differences in 
Table A3. Curve number values used for each combination of a hydrological soil group and a simplified land cover class. For each hydrological soil group, the corresponding texture classes according to the Belgian soil map are listed.

\begin{tabular}{lllr}
\hline $\begin{array}{l}\text { Hydrological } \\
\text { soil group }\end{array}$ & $\begin{array}{l}\text { Texture class according } \\
\text { to the Belgian soil map }\end{array}$ & Simplified land & Curve number \\
& cover class & \\
\hline A & P, S, Z, L-P-Z, P-Z, X, S-Z, A-Z & Built-up area & 77 \\
& (Sandy loam to sand) & Arable land/bare soil & 72 \\
& & Pasture/grassland & 39 \\
& & Forest & 25 \\
& & Open water & 0 \\
\hline B & A, E, G, L, U-L, U-L-S, A-G, A-L, E-Z & Built-up area & 85 \\
& (Light clay to loam) & Arable land/bare soil & 81 \\
& & Pasture/grassland & 61 \\
& & Forest & 55 \\
& & Open water & 0 \\
\hline D & U & Built-up area & 92 \\
& (Heavy clay) & Arable land/bare soil & 91 \\
& & Pasture/grassland & 80 \\
& & Forest & 77 \\
& O & Open water & 0 \\
\hline P & (Peat) & Open water & 0 \\
& Open water & All other land cover classes & 85 \\
\hline W & & All land cover classes & 0 \\
\hline
\end{tabular}

Table A4. Best-fitting parameter values, model efficiency and mean relative error (\%) for the calibrated parameters of STREAM.

\begin{tabular}{lrr}
\hline Calibration parameter & Dijle & Grote Nete \\
\hline$P_{\text {cal }}$ & 2.952 & 3.257 \\
$S_{\text {cal }}\left(\mathrm{m} \mathrm{d}^{-1} \%^{-1}\right)$ & $3.866 \times 10^{-4}$ & $1.057 \times 10^{-3}$ \\
$G_{\mathrm{cal}}\left(\mathrm{d}^{-1} \%^{-1}\right)$ & 0.157 & 0.250 \\
Nash-Sutcliffe model efficiency & 0.348 & 0.422 \\
Mean relative error $(\%)$ & 0.231 & 0.381 \\
\hline
\end{tabular}

the basin hydrology between the Dijle and Grote Nete are more pronounced than variability due to the climate and land cover scenarios (Fig. A5). While the different climate and land cover scenarios result in variability in the mean annual precipitation and actual evapotranspiration, the absolute values of the recharge rates remain stable with minimal variation over the different scenarios.

The STREAM simulations can be compared to other studies to check how realistic the modelled results are. For the Grote Nete basin under current conditions, Batelaan and De Smedt calculate a mean recharge rate of $282 \mathrm{~mm} \mathrm{yr}^{-1}$ using the WetSpass model, which matches well with the mean value of $286 \mathrm{~mm} \mathrm{yr}^{-1}$ found here using STREAM (Fig. A5) (Batelaan and De Smedt, 2001). For the Flemish part of the Dijle basin, they find a mean recharge percentage of $26 \%$ under current conditions (De Smedt and Batelaan, 2003). This estimate is lower than the mean value of $31.6 \%$ over all sce- narios found in this study, but given the low recharge percentages of built-up land and the absence of that land cover category in all land cover scenarios used here, the results of both models seem to converge relatively well.

The fluctuations in mean monthly discharge throughout the year are much larger for the Grote Nete River than for the Dijle River (Fig. A6). Differences between the climate scenarios are most pronounced during winter, with a delay in the maximal mean monthly discharge for scenarios 1 and 2, which can be related to the colder temperatures for these scenarios resulting in a delayed snowmelt season. The different land cover scenarios result in small differences in the mean monthly discharge, with higher flows for the land cover scenarios with little or no forest cover, which can be attributed to the lower evapotranspiration flux over cropland and grassland, compared to forest. Overall, changes in land cover affect the mean monthly discharge of the Dijle River more in comparison to the Grote Nete River.

In addition to the mean discharges, recurrence intervals allow us to study the changes in the frequency of peak flow events (Fig. A7). The different land cover scenarios result in increasing discharge values with decreasing forest cover, although this effect is larger for the Dijle River than for the Grote Nete River.

\section{A2 Modifications to the DigiBog peatland model}

The local peatland model used in this study is based on the 2015 version of the DigiBog peatland model, which was 
Table A5. Vegetation fractions of the land cover maps of the Dijle catchment, used for the different archaeological periods.

\begin{tabular}{lrrr}
\hline Period & Forest & Grassland/short vegetation [\%] & Cropland/bare soil [\%] \\
\hline Neolithic period [\%] & 86 & 7 & 7 \\
Bronze Age & 74 & 13 & 13 \\
Iron Age & 69 & 3 & 28 \\
Roman age & 66 & 17 & 17 \\
Early medieval & 29 & 23 & 48 \\
Late medieval-modern & 1 & 10 & 89 \\
\hline
\end{tabular}
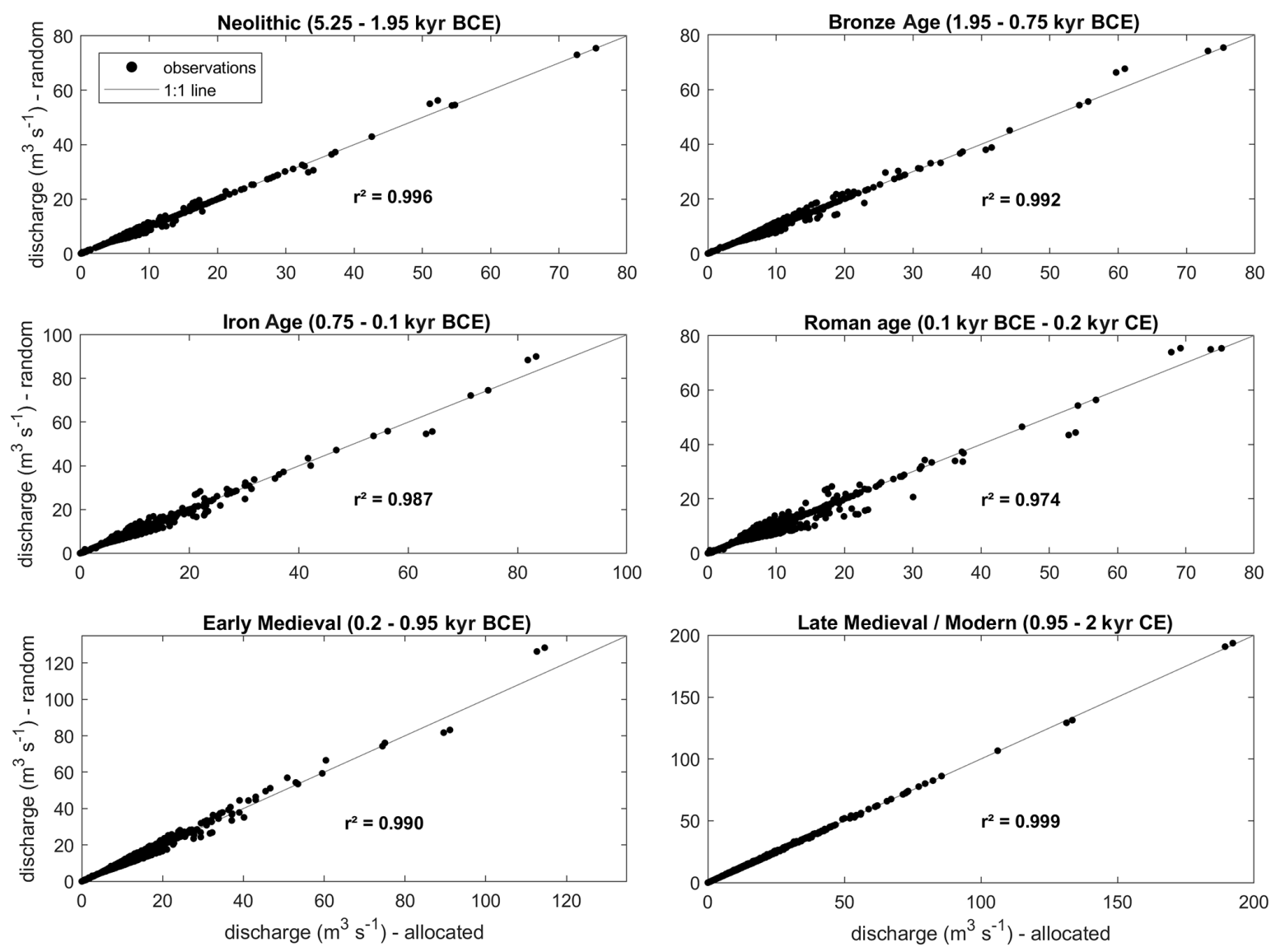

Figure A4. Scatterplots of the simulated discharge $\left(\mathrm{m}^{3} \mathrm{~s}^{-1}\right)$ for the realistic and randomly allocated land cover maps for each of the six archaeological periods (with indication of the coefficient of determination).

modified to be more applicable to an alluvial context. Firstly, the floodplain is assumed to consist of parallel river channels with peat bodies in between. The water table dynamics are calculated using Child's equation for elliptic bogs with the length of the ellipse (parallel to the river flow) being infinitely long (Eq. A1):

$\frac{\mathrm{d} H}{\mathrm{~d} t}=\frac{U}{\theta_{\mathrm{d}}}-\frac{K_{\mathrm{av}} H^{2}}{L^{2} \theta_{\mathrm{d}}}$

where $H$ is the water table elevation (m), $U$ is the net rainfall $(\mathrm{m}), \theta_{\mathrm{d}}$ is the drainable porosity of the peat $\left(\mathrm{m}^{3} \mathrm{~m}^{-3}\right)$, $K_{\mathrm{av}}$ is the peat profile transmissivity $\left(\mathrm{m}^{2} \mathrm{yr}^{-1}\right)$ and $L$ is the lateral extent of the bog, which equals half the spacing between the parallel drains (Morris et al., 2015).

Secondly, modifications were made to the calculation of the evapotranspiration fluxes. The annual potential evapotranspiration rate, calculated using the Thornthwaite method, is subdivided in soil evaporation and plant transpiration based on the leaf area index (Eqs. A2 and A3) (Williams et al., 1983):

$$
\begin{aligned}
& E_{\text {soil }}=E_{\text {pot }} e^{-0.4 \mathrm{LAI}} \\
& E_{\text {plant }}=E_{\text {pot }}-E_{\text {soil }},
\end{aligned}
$$



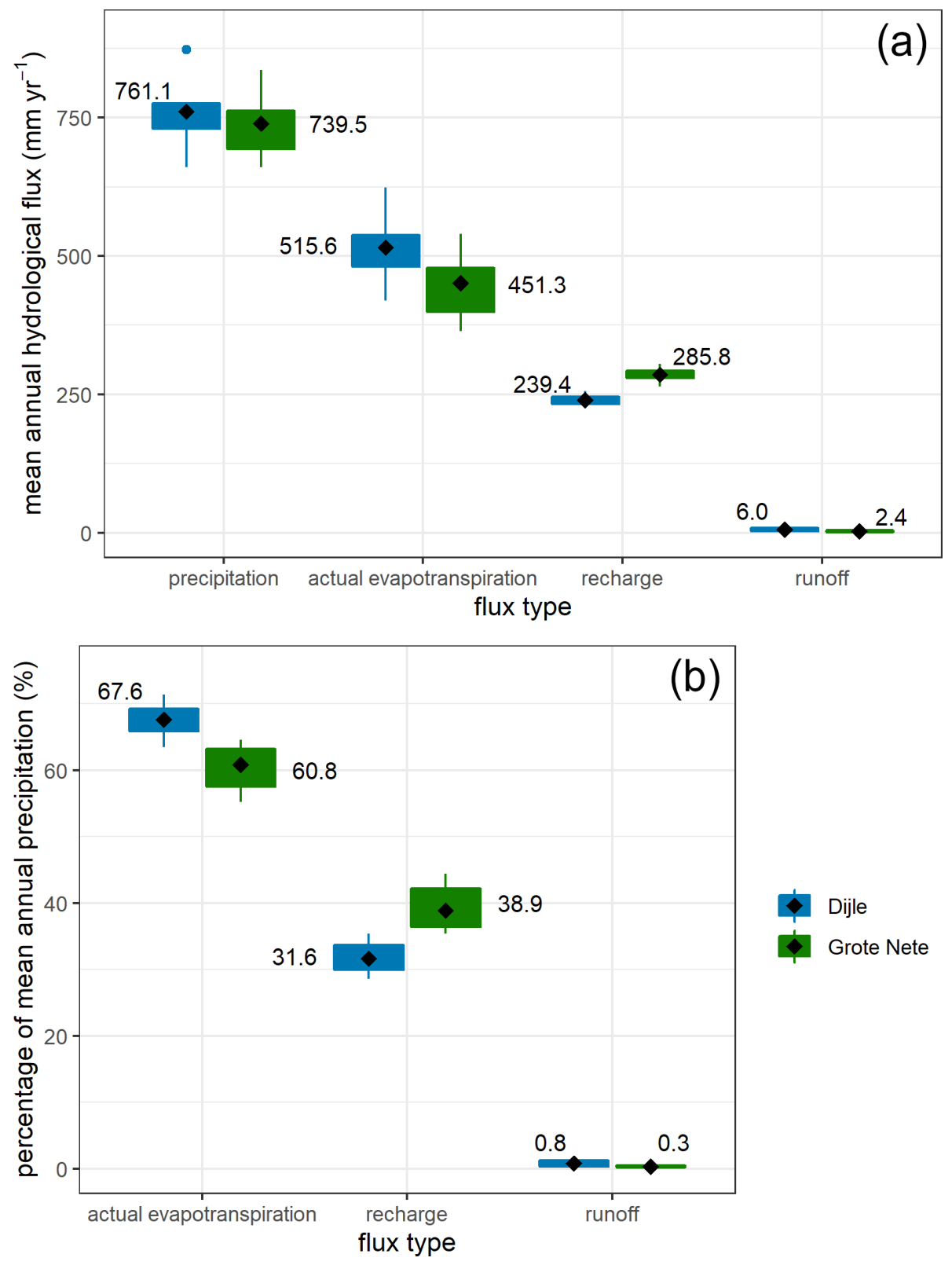

Figure A5. (a) Mean annual hydrological fluxes $\left(\mathrm{mm} \mathrm{yr}^{-1}\right)$ over the Dijle and Grote Nete basins for each combination of climate and land cover scenario $(n=30)$. (b) Relative mean annual hydrological fluxes as a percentage of the total annual precipitation over the Dijle and Grote Nete basins. The mean value is indicated by a black diamond. The numbers correspond to the mean value over all scenario combinations. The box indicates all values within the 25 th to 75 th percentile range, and the whiskers represent all values within the range from the 25 th percentile to 1.5 times the interquartile range to the 75 th percentile plus 1.5 times the interquartile range. Coloured dots represent all other values outside this range.

where $E_{\text {soil }}$ is the potential annual soil evaporation (m), $E_{\text {plant }}$ is the potential annual plant transpiration (m), $E_{\text {pot }}$ is the annual potential evapotranspiration and LAI is the leaf area index $\left(\mathrm{m}^{2} \mathrm{~m}^{-2}\right)$.

The soil evaporation component of the total actual evapotranspiration rate is calculated based on the depth of the water table (Eq. A4). It is assumed that the soil evaporation rate is at its maximal value when the water table is located be- tween the surface and a specific depth, at which water supply for evaporation is not limited. Once the water table depth increases further, the actual evaporation rate decreases with a linear trend until the depth for which the water supply for evaporation reaches zero (Price et al., 2003; Swinnen et al., 2019): 

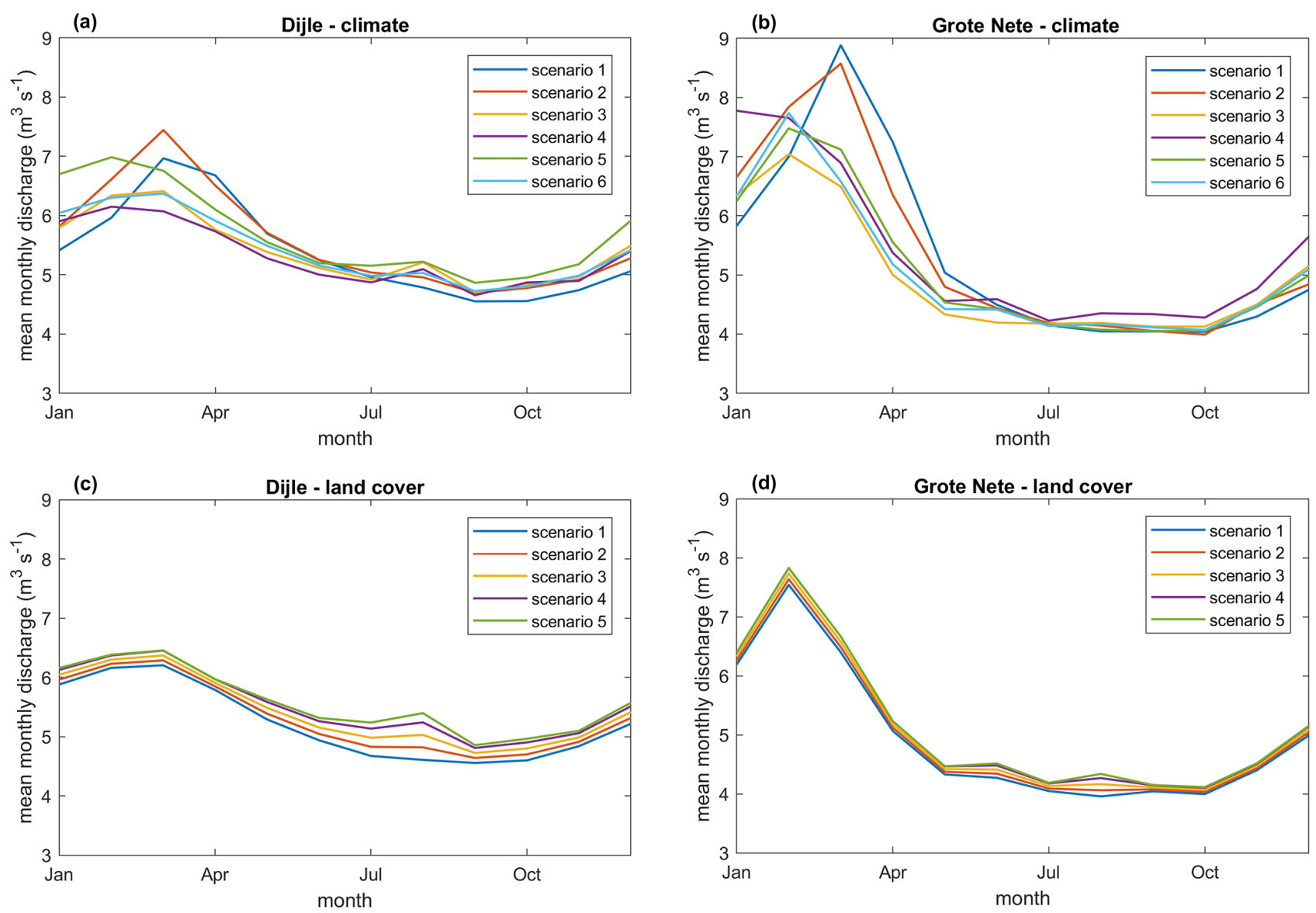

Figure A6. Simulated mean monthly discharge $\left(\mathrm{m}^{3} \mathrm{~s}^{-1}\right)$ for the Dijle River at Korbeek-Dijle (a, c) and the Grote Nete River at Hulshout (b, d) under the different climate scenarios for land cover scenario 3 (a, b) and under the different land cover scenarios for climate scenario 6 (c, d).

$\mathrm{AET}_{\text {soil }}=E_{\text {soil }} \frac{z_{2}-\mathrm{wt}}{z_{2}-z_{1}}$, for $z_{1} \leq \mathrm{wt} \leq z_{2}$,

where $\mathrm{AET}_{\text {soil }}$ is the actual soil evaporation rate $\left(\mathrm{m} \mathrm{yr}^{-1}\right)$, $E_{\text {soil }}$ is the potential annual soil evaporation rate $\left(\mathrm{m} \mathrm{yr}^{-1}\right)$, wt is the water table depth $(\mathrm{m}), z_{1}$ is the depth at which $\mathrm{AET}_{\text {soil }}$ starts to decrease and $z_{2}$ is below the depth at which $\mathrm{AET}_{\text {soil }}$ becomes zero.

The actual plant transpiration rate is dependent on both the vegetation type and the water table depth. It is assumed that the peat column is covered by a combination of tall vegetation (trees and shrubs) and short vegetation such as grasses, sedges and mosses, each occupying between 0 and $100 \%$ of the surface, with the sum of both percentages being always $100 \%$. Similar to Heinemeyer et al., different vegetation classes are assumed to have a specific maximal rooting depth (Heinemeyer et al., 2010). If the water table depth is at the maximal rooting depth, plants will still be able to transpire water due to the capillary rise of water into the rooted zone. As a result, the assumption is made that once the water table falls below the sum of the rooting depth and the height of capillary rise $\left(z_{\text {plant }}+z_{2}\right)$, the actual plant transpiration rate for this vegetation class falls to zero. Additionally, the assumption is made that the actual plant transpiration rate is maximal when the water table depth is equal to half this depth $\left(\left(z_{\text {plant }}+z_{2}\right) / 2\right)$. Similar to Bauer (2004), the rooting depth of the woody roots is assumed to be limited by the water table depth. As a result, the maximal rooting depth cannot exceed the long-term mean water table depth over the past 10 years, with a minimum value of $50 \mathrm{~cm}$ (Bauer, 2004).

Different plant species respond differently to high water tables. Here, the assumption is made that plants which are typical for wet conditions are able to grow and transpire water under high water table conditions, while the opposite is true for plants which are typical for drier environments. These plants will suffer from the waterlogged conditions and stop transpiring water. The preference of plant species with regard to moisture can be semi-quantified using the Ellenberg indicator value for moisture ( $f$ value), ranging from 1 to 12 , with higher values indicating water-tolerant species. The actual plant transpiration rate when the water table is at the surface is calculated based on the maximal actual transpi- 
(a)

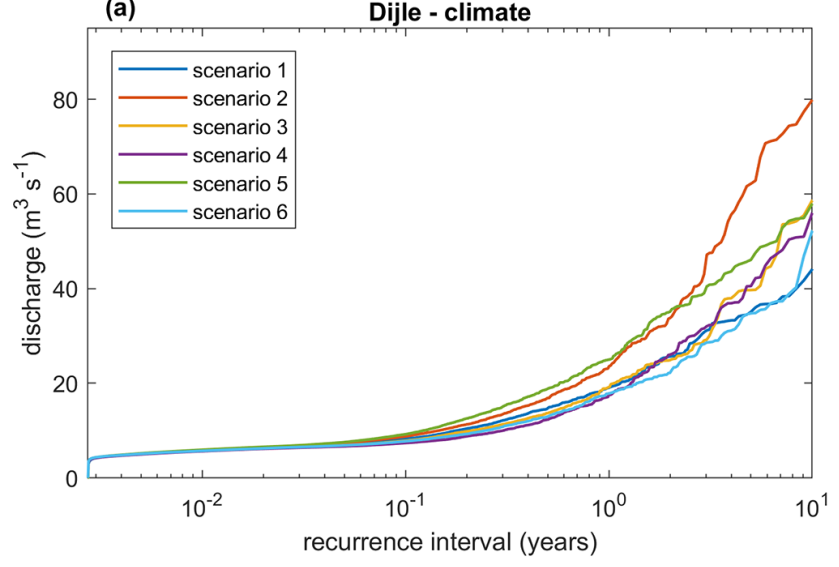

(c)

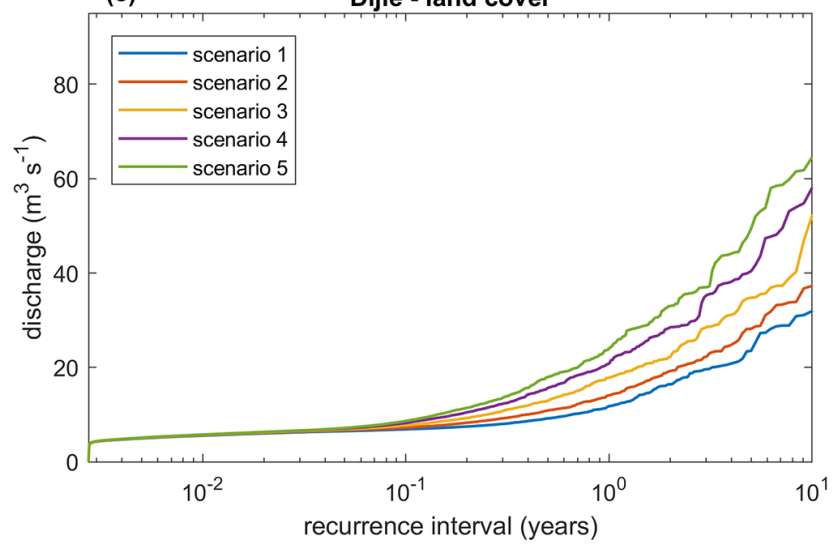

(b)

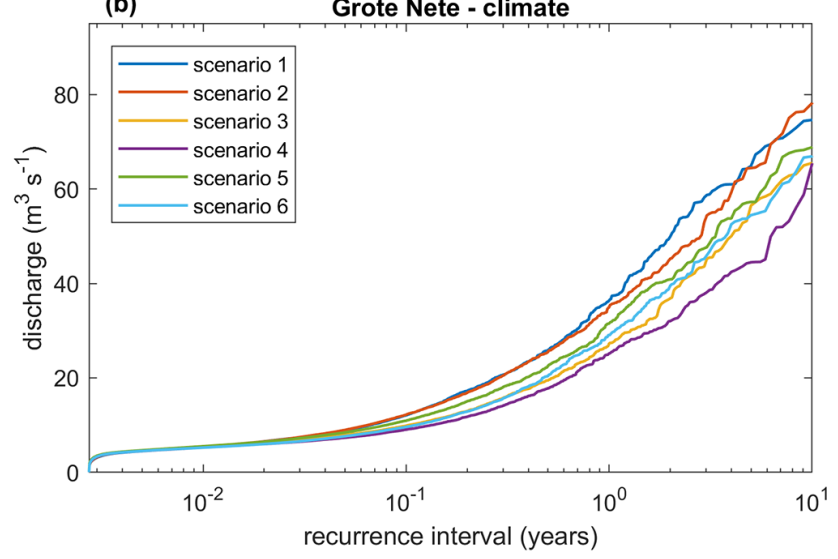

(d)

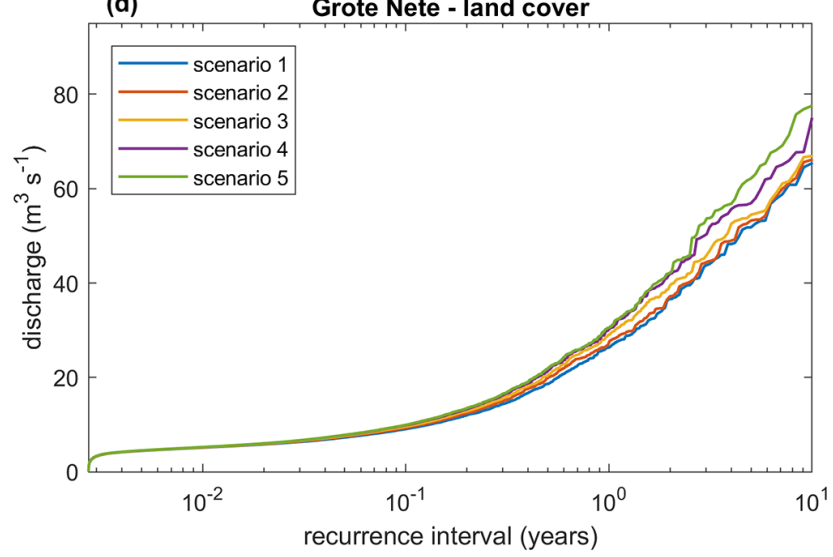

Figure A7. Recurrence intervals (years) for the simulated daily discharge $\left(\mathrm{m}^{3} \mathrm{~s}^{-1}\right)$ for the Dijle River at Korbeek-Dijle (a, c) and the Grote Nete River at Hulshout $(\mathbf{b}, \mathbf{d})$ under the different climate scenarios for land cover scenario 3 (a, b) and land cover scenarios for climate scenario $6(\mathbf{c}, \mathbf{d})$.
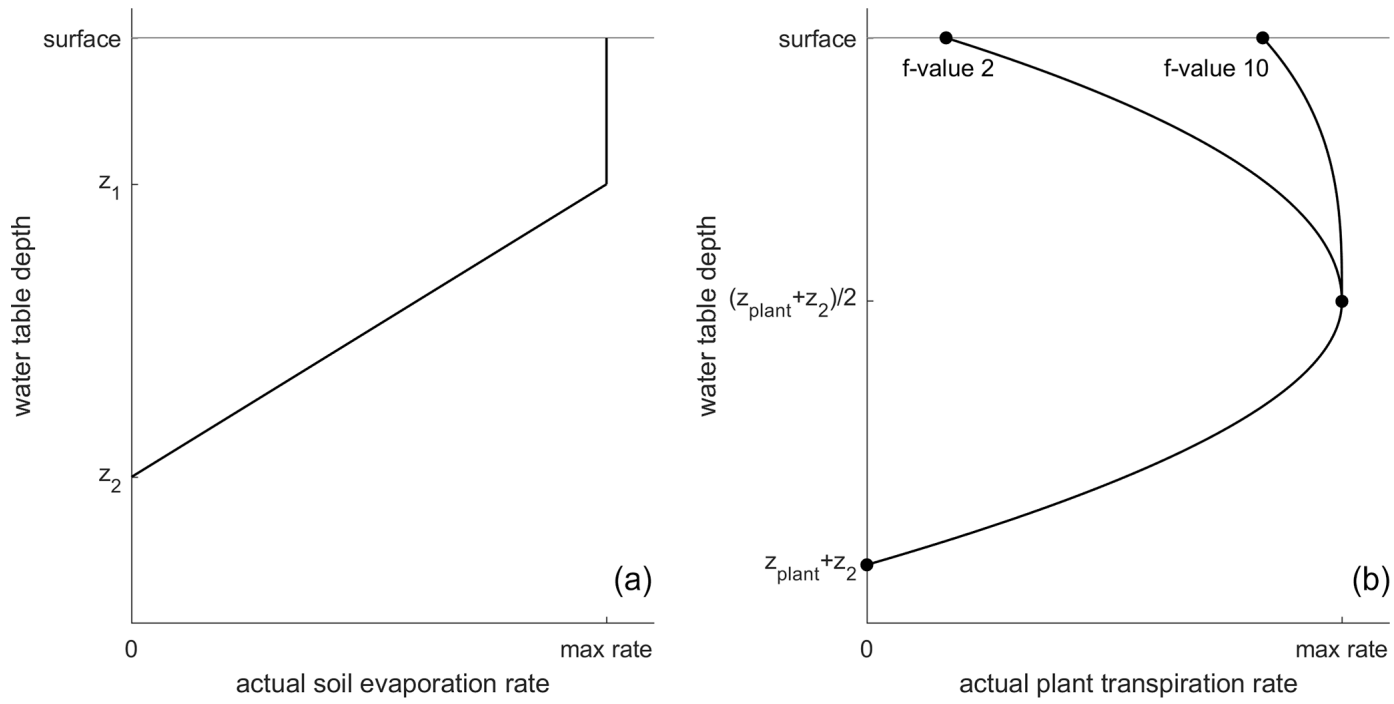

Figure A8. (a) Actual soil evaporation rate as a function of the water table depth. (b) Actual plant transpiration rate as a function of the water table depth and the Ellenberg indicator value for moisture ( $f$ value). Examples are shown for $f$ values of 2 and 10 . 
Table A6. Overview of the parameters used in the parameter sensitivity test, listing the standard value and the range over which the parameter is varied.

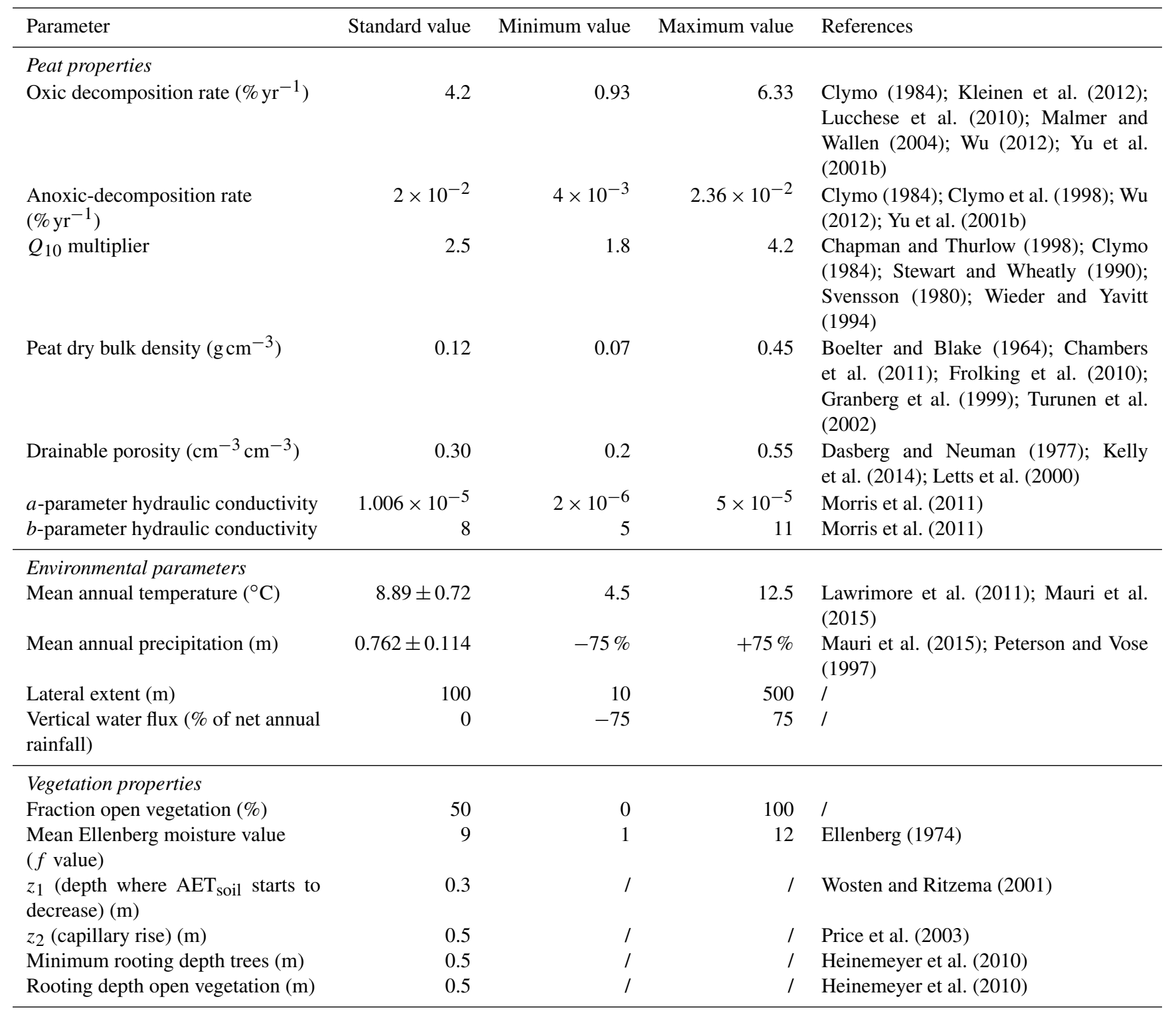

ration rate and the Ellenberg value (Eq. A5):

$\mathrm{AET}_{\text {plant, waterlogged }}=E_{\text {plant }} \cdot\left(\frac{\text { Ellenberg }-f}{12}\right)$,

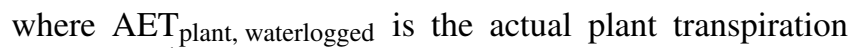
rate $\left(\mathrm{m} \mathrm{yr}^{-1}\right)$ under waterlogged conditions and Ellenberg $f$ is the average moisture value for the vegetation class under consideration. This means that plant species with an Ellenberg $f$ value of 12 (hydrophilic plant) will transpire at the maximal rate when the water table is located between the surface and half the rooting depth, while plant species with a low Ellenberg $f$ value will suffer from high water tables and thus will have lower rates of transpiration.
These assumptions result in defined actual transpiration rates for three water table depths (peat surface, half the maximal rooting depth and maximal rooting depth). A continuous function expressing the relationship between the actual transpiration rate and the water table depth is constructed using piecewise cubic Hermite interpolating polynomial splines based on the three known points. As a result, an actual plant transpiration rate can be calculated for any given water table depth (Fig. A8). The total actual evapotranspiration rate thus consists of the sum of the actual soil evaporation rate and the plant transpiration rates for both vegetation classes. 


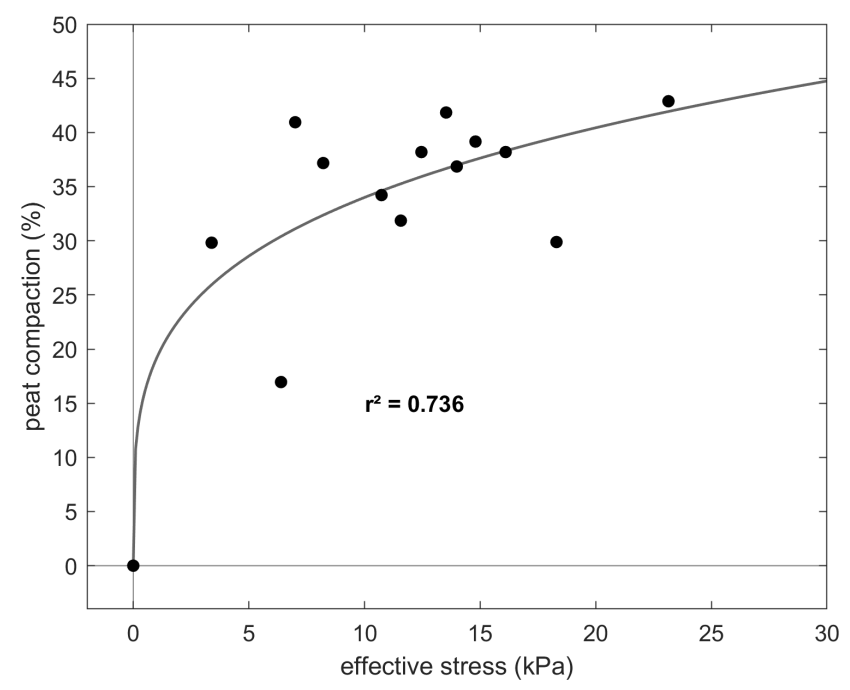

Figure A9. Peat compaction (\%) as a function of the effective stress exerted on the peat layer $(\mathrm{kPa})$. The fitted fourth root function is based on a dataset for central Canadian floodplains $(n=14)$ (Van Asselen et al., 2010).

\section{A3 Field data}

Given the idealized circumstances for which the model is developed, a detailed calibration and validation procedure is not possible. However, several datasets, which are available for the studied case studies, can be used to fine-tune specific model parameters and constrain the uncertainty on the simulated results. A first source of information consists of the measured peat thickness derived from a dataset of 295 soil corings across the study areas (Swinnen et al., 2020). Since the DigiBog model does not incorporate sediment dynamics, the measured peat thickness values need to be corrected for compaction after being buried by overlying mineral sediment. The compaction percentage is calculated using an empirical relationship, expressing the percentage of thickness reduction as a function of the effective stress of the overlying sediment. Based on a study of Van Asselen et al., compaction data from 14 buried floodplain peat deposits in the Cumberland Marshes (central Canada) were obtained, which were used to construct an empirical relationship (Eq. A6 and Fig. A9) (Van Asselen et al., 2010):

$C=14.78 \sqrt[4]{2.801 \sigma^{\prime}}$

where $C$ is the peat compaction, defined as the reduction of the peat volume, expressed as a percentage of the original volume and $\sigma^{\prime}$ is the effective stress exerted on the peat layer (kPa) (Van Asselen et al., 2010). This effective stress is calculated using Terzaghi's equation, with $\sigma$ being the stress of the overlying sediment $(\mathrm{kPa})$ and $u$ being the pore water pressure (kPa) (Eqs. A7-A9) (Terzaghi, 1943), as $\sigma^{\prime}=\sigma-u$

$\sigma=\rho_{\text {sed }} g h$,

where $\rho_{\text {sed }}$ is the saturated density of the overlying sediment $\left(\mathrm{kg} \mathrm{m}^{-3}\right), g$ is the gravity constant $\left(\mathrm{m} \mathrm{s}^{-2}\right)$ and $h$ is the thickness of the overlying sediment $(\mathrm{m})$ as

$u=\rho_{\mathrm{w}} g h_{\mathrm{w}}$,

where $\rho_{\mathrm{W}}$ is the density of the water $\left(\mathrm{kg} \mathrm{m}^{-3}\right), g$ is the gravity constant $\left(\mathrm{m} \mathrm{s}^{-2}\right)$ and $h_{\mathrm{w}}$ is the thickness of the water column overlying the peat layer $(\mathrm{m})$. Given the high water table depths in floodplain environments, the effective overburden stress is calculated under the assumption that the overlying sediments are water saturated.

The shape of Eq. (A6) implies that a low effective stress of overburden sediment leads to compaction percentages of $20 \%$ or more, with the compaction rate decreasing with further increasing effective overburden stress. This can be explained by the collapse of the physical structure of uncompacted peat at low effective-stress values. Based on this relationship, the compaction-corrected peat thickness can be calculated for all peat layers found in the soil coring dataset, which can be compared with simulated peat thickness values. This results in a mean-corrected peat thickness of $1.60 \mathrm{~m}$ for the Dijle and $0.56 \mathrm{~m}$ for the Grote Nete. Overall, the corrected thickness values range between 0.1 and $6.7 \mathrm{~m}$, although the higher thicknesses are only found in the Dijle River floodplains (Fig. A10).

In addition, available data on the dry bulk density and organic carbon content of the peat for each of the studied river systems (70 samples) can be used to calculate representative dry bulk density values for peat, correcting for both compaction due to burial and the presence of mineral sediment (Eq. A10):

$\mathrm{DBD}_{\mathrm{cor}}=\mathrm{DBD}(1-C)\left(\frac{\% \mathrm{OC}}{0.58}\right)$,

where $\mathrm{DBD}_{\mathrm{cor}}$ is the dry bulk density of the peat $\left(\mathrm{g} \mathrm{cm}^{-3}\right)$, corrected for compaction and the presence of mineral particles; DBD is the mean measured dry bulk density for peat $\left(\mathrm{g} \mathrm{cm}^{-3}\right) ; C_{\mathrm{av}}$ is the compaction percentage for the region (loess belt and sand belt); and \%OC is the mean organic carbon content of floodplain peat for the region. Here, the organic matter present within the peat layer is assumed to have an organic carbon fraction of 0.58 , which corresponds to the van Bemmelen factor. Using Eq. (A10), a mean dry bulk density and standard deviation of the mean for the organic matter fraction of peat was $0.11 \pm 0.01 \mathrm{~g} \mathrm{~cm}^{-3}$ for the Dijle River and $0.13 \pm 0.01 \mathrm{~g} \mathrm{~cm}^{-3}$ for the Grote Nete River. Based on these calculations, the standard value for the dry bulk density of peat used in model simulations is set to $0.12 \mathrm{~g} \mathrm{~cm}^{-3}$. 


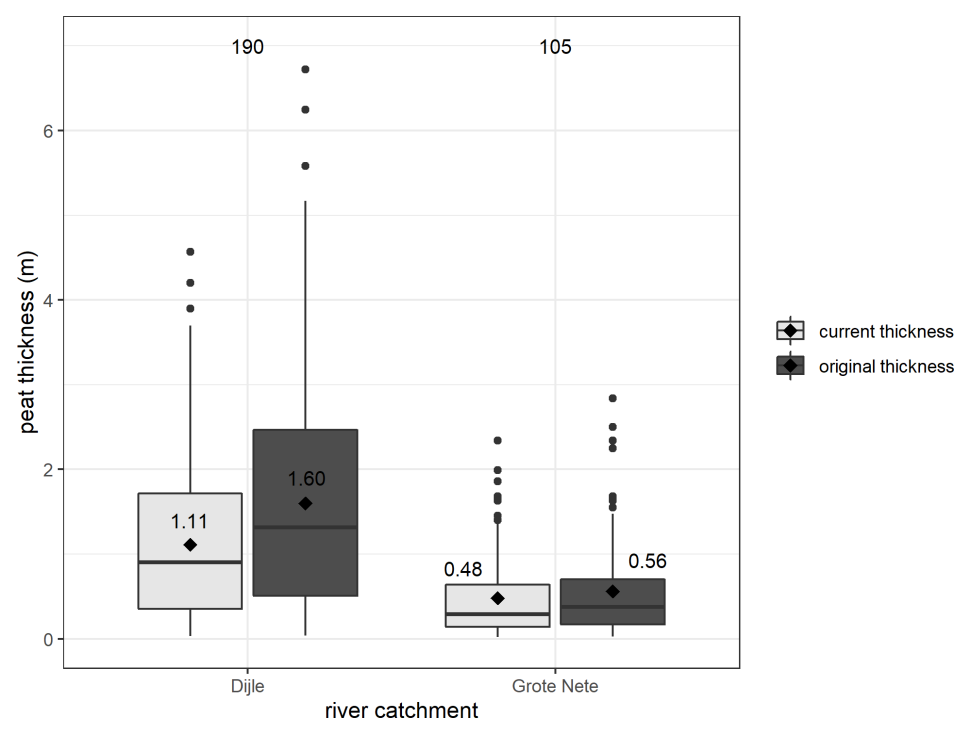

Figure A10. Boxplots of the measured (current thickness) and compaction-corrected (original thickness) peat thickness for the Dijle and Grote Nete floodplains. The median and mean value are given by a horizontal line and black diamond. The values in the box indicate the mean value. The box represents all values within the 25 th to 75 th percentile range, and the whiskers represent all values within the range from the 25 th percentile to 1.5 times the interquartile range to the 75 th percentile plus 1.5 times the interquartile range. Black dots represent all other values outside this range.

\section{A4 Sensitivity analysis}

For each of the model parameters considered in the sensitivity analysis, the simulated range, standard value and references are listed in the table below. For the model parameters related to the calculation of the evapotranspiration, not enough information was found in the literature. As a result, these model parameters were not included in the sensitivity analysis, and their value is kept at the standard value (Table A6).

Code availability. The model code (MATLAB) used for the simulations with STREAM and DigiBog is available online at https://doi.org/10.17632/vrz6gm7nhp.1 (Swinnen, 2021). The original 1D version of DigiBog on which this code is based can be found in the Supplement of Morris et al. (2015, https://doi.org/10.1002/2015GL066824). The original version of STREAM on which this code is based can be found on https: //research.vu.nl/ws/portalfiles/portal/1936669/f12.pdf (Aerts and Bouwer, 2003). In addition, STREAM makes use of the TopoToolbox GIS (geographic information system) package for MATLAB (Schwanghart and Scherler, 2014, https://doi.org/10.5194/esurf-21-2014).

Data availability. The river discharge data used to calibrate STREAM are freely available at https://www.waterinfo.be (VMM, 2021a, b). The temperature and precipitation data were obtained from the Belgian Royal Meteorological Institute (KMI). The reproduction or distribution of the data in this publication is not allowed under the agreement with the KMI.
Author contributions. This project was conceptualized by WS, NB and GV. WS carried out the modelling work and analysis. NB and GV supervised the research. WS, NB and GV wrote the manuscript.

Competing interests. The contact author has declared that neither they nor their co-authors have any competing interests.

Disclaimer. Publisher's note: Copernicus Publications remains neutral with regard to jurisdictional claims in published maps and institutional affiliations.

Financial support. This research has been supported by the Fonds Wetenschappelijk Onderzoek (grant nos. G0A6317N, 1167019N and S003017N).

Review statement. This paper was edited by Gwenaël Abril and reviewed by Paul J. Morris and one anonymous referee.

\section{References}

Aerts, J. C. J. H. and Bouwer, L. M.: Stream SE Manual version 2.0. (IVM Report; No. R-03/13). Dept. of Spatial Analysis and Decision Support, available at: https://research.vu.nl/ws/portalfiles/ portal/1936669/f12.pdf (last access: 1 May 2021), 2003.

Aerts, J. C. J. H., Kriek, M., and Schepel, M.: STREAM (Spatial Tools for River Basins and Environment and Analysis of Man- 
agement Options): set up and requirements, Phys. Chem. Earth Pt. B, 24, 591-595, 1999.

Aerts, J. C. J. H., Renssen, H., Ward, P. J., De Moel, H., Odada, E., Bouwer, L. M., and Goosse, H.: Sensitivity of global river discharges under Holocene and future climate conditions, Geophys. Res. Lett., 33, L19401, https://doi.org/10.1029/2006GL027493, 2006.

Baird, A. J., Morris, P. J., and Belyea, L. R.: The DigiBog peatland development model 1: rationale, conceptual model, and hydrological basis, Ecohydrology, 5, 242-255, https://doi.org/10.1002/eco.2, 2012.

Baird, A. J., Low, R., Young, D., Swindles, G. T., Lopez, O. R., and Page, S.: High permeability explains the vulnerability of the carbon store in drained tropical peatlands, Geophys. Res. Lett., 44, 1333-1339, https://doi.org/10.1002/2016GL072245, 2017.

Ballabio, C., Panagos, P., and Monatanarella, L.: Mapping topsoil physical properties at European scale using the LUCAS database, Geoderma, 261, 110-123, https://doi.org/10.1016/j.geoderma.2015.07.006, 2016.

Batelaan, O. and De Smedt, F.: WetSpass: A flexible, GIS based, distributed recharge methodology for regional groundwater modelling, in: IAHS-AISH Publication, 11-18, 2001.

Bauer, I. E.: Modelling effects of litter quality and environment on peat accumulation over different time-scales, J. Ecol., 92, 661674, https://doi.org/10.1111/j.0022-0477.2004.00905.x, 2004.

Beerten, K., Dreesen, R., Janssen, J., and Van Uytven, D.: The Campine Plateau, in: Landscapes and Landforms of Belgium and Luxembourg, edited by: Demoulin, A., Springer, Cham, Switzerland, p. 423, 2017.

Beven, K.: A manifesto for the equifinality thesis, J. Hydrol., 320, 18-36, https://doi.org/10.1016/j.jhydrol.2005.07.007, 2006.

Billett, M. F., Palmer, S. M., Hope, D., Deacon, C., StoretonWest, R., Hargreaves, K. J., Flechard, C., and Fowler, D.: Linking land-atmosphere-stream carbon fluxes in a lowland peatland system, Global Biogeochem. Cy., 18, GB1024, https://doi.org/10.1029/2003GB002058, 2004.

Boelter, D. H. and Blake, G. R.: Importance of Volumetric Expression of Water Contents of Organic Soils, Soil Sci. Soc. Am. J., 28, 176-178, https://doi.org/10.2136/sssaj1964.03615995002800020015x, 1964.

Boucher, É., Arseneault, D., and Hétu, B.: Late Holocene development of a floodplain along a small meandering stream, northern Québec, Canada, Geomorphology, 80, 267-281, https://doi.org/10.1016/j.geomorph.2006.02.014, 2006.

Broothaerts, N., Verstraeten, G., Notebaert, B., Assendelft, R., Kasse, C., Bohncke, S., and Vandenberghe, J.: Sensitivity of floodplain geoecology to human impact: A Holocene perspective for the headwaters of the Dijle catchment, central Belgium, Holocene, 23, 1403-1414, https://doi.org/10.1177/0959683613489583, 2013.

Broothaerts, N., Verstraeten, G., Kasse, C., Bohncke, S., Notebaert, B., and Vandenberghe, J.: From natural to humandominated floodplain geoecology - A Holocene perspective for the Dijle catchment, Belgium, Anthropocene, 8, 46-58, https://doi.org/10.1016/j.ancene.2014.12.001, 2014a.

Broothaerts, N., Notebaert, B., Verstraeten, G., Kasse, C., Bohncke, S., and Vandenberghe, J.: Non-uniform and diachronous Holocene floodplain evolution: A case study from the Dijle catchment, Belgium, J. Quaternary Sci., 29, 351-360, https://doi.org/10.1002/jqs.2709, 2014b.

Broothaerts, N., Verstraeten, G., Kasse, C., Bohncke, S., Notebaert, B., and Vandenberghe, J.: Reconstruction and semi-quantification of human impact in the Dijle catchment, central Belgium: A palynological and statistical approach, Quaternary Sci. Rev., 102, 96-110, https://doi.org/10.1016/j.quascirev.2014.08.006, 2014c.

Brown, A. G., Lespez, L., Sear, D. A., Macaire, J. J., Houben, P., Klimek, K., Brazier, R. E., Van Oost, K., and Pears, B.: Natural vs anthropogenic streams in Europe: History, ecology and implications for restoration, river-rewilding and riverine ecosystem services, Earth-Sci. Rev., 180, 185-205, https://doi.org/10.1016/j.earscirev.2018.02.001, 2018.

De Brue, H.: Modelling the long-term evolution of anthropogenic land cover and environmental impact in the central Belgian Loess Belt, KU Leuven, Leuven, Belgium, 2016.

De Brue, H. and Verstraeten, G.: Impact of the spatial and thematic resolution of Holocene anthropogenic land-cover scenarios on modeled soil erosion and sediment delivery rates, Holocene, 24, 67-77, https://doi.org/10.1177/0959683613512168, 2014.

Burny, J.: Bijdrage tot de historische ecologie van de Limburgse Kempen (1910-1950). Tweehonderd gesprekken samengevat, Stichting Natuurpublicaties Limburg, Maastricht, the Netherlands, 1999.

Candel, J. H. J., Makaske, B., Storms, J. E. A., and Wallinga, J.: Oblique aggradation: a novel explanation for sinuosity of lowenergy streams in peat-filled valley systems, Earth Surf. Proc. Land., 42, 2679-2696, https://doi.org/10.1002/esp.4100, 2017.

Chambers, F. M., Beilman, D. W., and Yu, Z.: Methods for determining peat humification and for quantifying peat bulk density, organic matter and carbon content for palaeostudies of climate and peatland carbon dynamics, Mires Peat, 7, 1-10, 2011.

Chapman, S. J. and Thurlow, M.: Peat respiration at low temperatures, Soil Biol. Biochem., 30, 1013-1021, https://doi.org/10.1016/S0038-0717(98)00009-1, 1998.

Childs, E. C.: An introduction to the Physical Principles of Soil Water Phenomena, John Wiley and Sons, London, 1969.

Clymo, R. S.: The Limits to Peat Bog Growth, Philos. T. R. Soc. B, 303, 605-654, https://doi.org/10.1098/rstb.1984.0002, 1984.

Clymo, R. S., Turunen, J., and Tolonen, K.: Carbon Accumulation in Peatland, Oikos, 81, 368-388, https://doi.org/10.2307/3547057, 1998.

Comas, X., Slater, L., and Reeve, A.: Geophysical evidence for peat basin morphology and stratigraphic controls on vegetation observed in a Northern Peatland, J. Hydrol., 295, 173-184, https://doi.org/10.1016/j.jhydrol.2004.03.008, 2004.

Dasberg, S. and Neuman, S. P.: Peat hydrology in the Hula basin, Israel: I. Properties of peat, J. Hydrol., 32, 219-239, 1977.

De Smedt, F.: Paleogeografie en kwartair-geologie van het confluentiegebied Dijle-Demer, Acta Geogr. Lovan., Vol. 11, 141 pp., KUL Geografisch Instituut, Leuven, Belgium, 1973.

De Smedt, F. and Batelaan, O.: Investigation of the human impact on regional groundwater systems, Trans. Ecol. Environ., 64, 1145-1153, 2003.

Diefenderfer, H. L. and Montgomery, D. R.: Pool spacing, channel morphology, and the restoration of tidal forested wetlands of the Columbia River, U. S. A., Restor. Ecol., 17, 158-168, https://doi.org/10.1111/j.1526-100X.2008.00449.x, 2009. 
Dondeyne, S., Vanierschot, L., Langohr, R., Van Ranst, E., and Deckers, J.: The soil map of the Flemish region converted to the 3rd edition of the World Reference Base for soil resources, Departement Leefmilieu, Natuur \& Energie, 2014.

EEA: CORINE Land Cover Project, published by the Commission of the European Communities, Departement Leefmilieu, Natuur \& Energie, Brussels, 1995.

Ellenberg, H.: Zeigerwerte der Gefässpflanzen Mitteleuropas, Scripta geobotanica, Götingen, 1974.

Frolking, S., Roulet, N. T., Tuittila, E., Bubier, J. L., Quillet, A., Talbot, J., and Richard, P. J. H.: A new model of Holocene peatland net primary production, decomposition, water balance, and peat accumulation, Earth Syst. Dynam., 1, 1-21, https://doi.org/10.5194/esd-1-1-2010, 2010.

Gellens-Meulenberghs, F. and Gellens, D.: L'evapotranspiration potentielle en Belgique: variabilité spatiale et temporelle, in: Institut Royal Meteorologique de Belgique, publication Série A no. 130, European Environment Agency, Copenhagen, 1-44, 1992.

Goedseels, V. and Vanhautte, L.: Hoeven op land gebouwd, Lannoo, Tielt, 1983.

Goossens, D. and Riksen, M. J. P. M.: De inlandse zandverstuivingen in België en Nederland: historiek en verband met klimaat en landbouwactiviteit, Acta Geogr. Lovan., 38, 323-336, 2009.

Gradziński, R., Baryła, J., Doktor, M., Gmur, D., Gradziński, M., K?dzior, A., Paszkowski, M., Soja, R., Zieliński, T., and Zurek, S.: Vegetation-controlled modern anastomosing system of the upper Narew River (NE Poland) and its sediments, Sediment. Geol., 157, 253-276, https://doi.org/10.1016/S00370738(02)00236-1, 2003.

Granberg, G., Grip, H., Ottosson Löfvenius, M., Sundh, I., Svensson, B. H., and Nilsson, M.: A simple model for simulation of water content, soil frost, and soil temperatures in boreal mixed mires, Water Resour. Res., 35, 3771-3782, https://doi.org/10.1029/1999WR900216, 1999.

Gullentops, F., Bogemans, F., and De Moor, G.: Quaternary lithostratigraphic units (Belgium), Geol. Belg., 4, 153-164, 2001.

Heinemeyer, A., Croft, S., Garnett, M. H., Gloor, E., Holden, J., Lomas, M. R., and Ineson, P.: The MILLENNIA peat cohort model: Predicting past, present and future soil carbon budgets and fluxes under changing climates in peatlands, Clim. Res., 45, 207-226, https://doi.org/10.3354/cr00928, 2010.

Herbosch, A. and Verniers, J.: Stratigraphy of the lower palaeozoic of the Brabant Massif, Belgium. part I: The Cambro-Ordovician from the Halle and Ottignies groups, Geol. Belg., 16, 49-65, 2013.

Hilbert, D. W., Roulet, N., and Moore, T.: Modelling and analysis of peatlands as dynamical systems, J. Ecol., 88, 230-242, 2000.

Hosia, L.: Pienten uomien virtausvastuskerroin, National Board of Waters, Finland, Helsinki, 1980.

Householder, J. E., Janovec, J. P., Tobler, M. W., Page, S., and Lähteenoja, O.: Peatlands of the Madre de Dios River of Peru: Distribution, Geomorphology, and Habitat Diversity, Wetlands, 32, 359-368, https://doi.org/10.1007/s13157-012-0271-2, 2012.

Juutinen, S., Väliranta, M., Kuutti, V., Laine, A. M., Virtanen, T., Seppä, H., Weckström, J., and Tuittila, E.: Short-term and longterm carbon dynamics in a northern peatland-stream-lake continuum: A catchment approach, J. Geophys. Res.-Biogeo., 118, 171-183, https://doi.org/10.1002/jgrg.20028, 2013.
Kelly, T. J., Baird, A. J., Roucoux, K. H., Baker, T. R., Honorio Coronado, E. N., Ríos, M., and Lawson, I. T.: The high hydraulic conductivity of three wooded tropical peat swamps in northeast Peru: Measurements and implications for hydrological function, Hydrol. Process., 28, 3373-3387, https://doi.org/10.1002/hyp.9884, 2014.

Kleinen, T., Brovkin, V., and Schuldt, R. J.: A dynamic model of wetland extent and peat accumulation: results for the Holocene, Biogeosciences, 9, 235-248, https://doi.org/10.5194/bg-9-2352012, 2012.

Knoben, W. J. M., Freer, J. E., and Woods, R. A.: Technical note: Inherent benchmark or not? Comparing Nash-Sutcliffe and KlingGupta efficiency scores, Hydrol. Earth Syst. Sci., 23, 4323-4331, https://doi.org/10.5194/hess-23-4323-2019, 2019.

Kumaran, N. K. P., Padmalal, D., Limaye, R. B., Vishnu Mohan, S., Jennerjahn, T., and Gamre, P. G.: Tropical peat and peatland development in the floodplains of the Greater Pamba Basin, South-western India during the Holocene, PLoS One, 11, 1-21, https://doi.org/10.1371/journal.pone.0154297, 2016.

Lappalainen, M., Koivusalo, H., Karvonen, T., and Laurén, A.: Sediment transport from a peatland forest after ditch network maintenance: a modelling approach, Boreal Environ. Res., 15, 595-612, 2010.

Lawrimore, J. H., Menne, M. J., Gleason, B. E., Williams, C. N., Wuertz, D. B., Vose, R. S., and Rennie, J.: An overview of the Global Historical Climatology Network monthly mean temperature data set, version 3, J. Geophys. Res.-Atmos., 116, D19121, https://doi.org/10.1029/2011JD016187, 2011.

Lespez, L., Viel, V., Rollet, A. J., and Delahaye, D.: Geomorphology The anthropogenic nature of present-day low energy rivers in western France and implications for current restoration projects, Geomorphology, 251, 64-76, https://doi.org/10.1016/j.geomorph.2015.05.015, 2015a.

Lespez, L., Viel, V., Rollet, A. J., and Delahaye, D.: Geomorphology The anthropogenic nature of present-day low energy rivers in western France and implications for current restoration projects, Geomorphology, 251, 64-76, https://doi.org/10.1016/j.geomorph.2015.05.015, 2015b.

Letts, M. G., Comer, N. T., Roulet, N. T., Skarupa, M. R., and Verseghy, D. L.: Parametrization of peatland hydraulic properties for the Canadian land surface scheme, Atmos. Ocean, 38, 141160, https://doi.org/10.1080/07055900.2000.9649643, 2000.

Lieth, H.: Primary production: Terrestrial ecosystems, Hum. Ecol., 1, 303-332, 1973.

Lieth, H. and Box, E. O.: Evapotranspiration and primary productivity: Thornthwaite Memorial Model, Publ. Climatol., 25, 37-46, 1972.

Lucchese, M., Waddington, J. M., Poulin, M., Pouliot, R., Rochefort, L., and Strack, M.: Organic matter accumulation in a restored peatland: Evaluating restoration success, Ecol. Eng., 36, 482-488, https://doi.org/10.1016/j.ecoleng.2009.11.017, 2010.

Makaske, B.: Anastomosing rivers: A review of their classification, origin and sedimentary products, Earth-Sci. Rev., 53, 149-196, https://doi.org/10.1016/S0012-8252(00)00038-6, 2001.

Malmer, N. and Wallen, B.: Input rates, decay losses and accumulation rates of carbon in bogs during the last millennium: internal processes and environmental changes, Holocene, 14, 111-117, 2004. 
Mann, D. H., Groves, P., Reanier, R. E., and Kunz, M. L.: Floodplains, permafrost, cottonwood trees, and peat: What happened the last time climate warmed suddenly in arctic Alaska?, Quaternary Sci. Rev., 29, 3812-3830, https://doi.org/10.1016/j.quascirev.2010.09.002, 2010.

Marttila, H., Tammela, S., and Kløve, B.: Hydraulic Geometry, Hydraulics and Sediment Properties of Forest Brooks after Extensive Erosion from Upland Peatland Drainage, Open J. Mod. Hydrol., 2, 59-69, 2012.

Mauri, A., Davis, B. A. S., Collins, P. M., and Kaplan, J. O.: The climate of Europe during the Holocene: A gridded pollen-based reconstruction and its multiproxy evaluation, Quaternary Sci. Rev., 112, 109-127, https://doi.org/10.1016/j.quascirev.2015.01.013, 2015.

Medeiros, S. C., Hagen, S. C., and Weishampel, J. F.: Comparison of floodplain surface roughness parameters derived from land cover data and field measurements, J. Hydrol., 452-453, 139149, https://doi.org/10.1016/j.jhydrol.2012.05.043, 2012a.

Medeiros, S. C., Hagen, S. C., and Weishampel, J. F.: Comparison of floodplain surface roughness parameters derived from land cover data and field measurements, J. Hydrol., 452-453, 139149, https://doi.org/10.1016/j.jhydrol.2012.05.043, 2012b.

Moeletsi, M. E., Walker, S., and Hamandawana, H.: Comparison of the Hargreaves and Samani equation and the Thornthwaite equation for estimating dekadal evapotranspiration in the Free State Province, South Africa, Phys. Chem. Earth, 66, 4-15, https://doi.org/10.1016/j.pce.2013.08.003, 2013.

Moriasi, D. N., Arnold, J. G., Van Liew, M. W., Bingner, R. L., Harmel, R. D., and Veith, T. L.: Model Evaluation Guidelines for Systematic Quantification of Accuracy in Watershed Simulations, T. ASABE, 50, 885-900, https://doi.org/10.13031/2013.23153, 2007.

Morris, P. J., Belyea, L. R., and Baird, A. J.: Ecohydrological feedbacks in peatland development: A theoretical modelling study, J. Ecol., 99, 1190-1201, https://doi.org/10.1111/j.13652745.2011.01842.x, 2011.

Morris, P. J., Baird, A. J., and Belyea, L. R.: The DigiBog peatland development model 2: ecohydrological simulations in 2D, Ecohydrology, 5, 256-268, https://doi.org/10.1002/eco.2, 2012.

Morris, P. J., Baird, A. J., Young, D. M., and Swindles, G. T.: Untangling climate signals from autogenic changes in long-term peatland development, Geophys. Res. Lett., 42, 10788-10797, https://doi.org/10.1002/2015GL066824, 2015.

Mullenders, W. and Gullentops, F.: Palynologisch en geologisch onderzoek in de alluviale vlakte van de Dijle te Heverlee-Leuven, Agricultura, 5, 57-64, 1957.

Mullenders, W., Gullentops, F., Lorent, J., Coremans, M., and Gilot, E.: Le remblement de la vallée de la Nethen, Acta Geogr. Lovan., 4, 169-181, 1966.

Nanson, R. A.: The evolution of peat-swamp channels and organic floodplains, barrington tops, New South Wales, Australia, Geogr. Res., 47, 434-448, https://doi.org/10.1111/j.17455871.2009.00596.x, 2009.

Nanson, R. A., Nanson, G. C., and Huang, H. Q.: The hydraulic geometry of narrow and deep channels; evidence for flow optimisation and controlled peatland growth, Geomorphology, 117, 143154, https://doi.org/10.1016/j.geomorph.2009.11.021, 2010.

Nash, J. E. and Sutcliffe, J. V.: River Flow Forecasting Through Conceptual Models Part I-a Discussion of Princi- ples, J. Hydrol., 10, 282-290, https://doi.org/10.1016/00221694(70)90255-6, 1970.

Notebaert, B. and Verstraeten, G.: Sensitivity of West and Central European river systems to environmental changes during the Holocene: A review, Earth-Sci. Rev., 103, 163-182, https://doi.org/10.1016/j.earscirev.2010.09.009, 2010.

Notebaert, B., Verstraeten, G., Rommens, T., Vanmontfort, B., Govers, G., and Poesen, J.: Establishing a Holocene sediment budget for the river Dijle, Catena, 77, 150-163, https://doi.org/10.1016/j.catena.2008.02.001, 2009.

Notebaert, B., Verstraeten, G., Ward, P., Renssen, H., and Van Rompaey, A.: Modeling the sensitivity of sediment and water runoff dynamics to Holocene climate and land use changes at the catchment scale, Geomorphology, 126, 18-31, https://doi.org/10.1016/j.geomorph.2010.08.016, 2011.

Peterson, T. C. and Vose, R. S.: An overview of the Global Historical Climatology Network temperature database, B. Am. Meteorol. Soc., 78, 2837-2849, https://doi.org/10.1175/15200477(1997)078<2837:AOOTGH>2.0.CO;2, 1997.

Polvi, L. E. and Wohl, E.: The beaver meadow complex revisited - the role of beavers in post-glacial floodplain development, Earth Surf. Proc. Land., 37, 332-346, https://doi.org/10.1002/esp.2261, 2012.

Price, J. S., Heathwaite, A. L., and Baird, A.: Hydrological processes in abandoned and restored peatlands, Wetl. Ecol. Manag., 11, 65-83, 2003.

Renssen, H., Lougheed, B. C., Aerts, J. C. J. H., de Moel, H., Ward, P. J., and Kwadijk, J. C. J.: Simulating long-term Caspian Sea level changes: The impact of Holocene and future climate conditions, Earth Planet. Sc. Lett., 261, 685-693, https://doi.org/10.1016/j.epsl.2007.07.037, 2007.

Ritter, A. and Muñoz-Carpena, R.: Performance evaluation of hydrological models: Statistical significance for reducing subjectivity in goodness-of-fit assessments, J. Hydrol., 480, 33-45, https://doi.org/10.1016/j.jhydrol.2012.12.004, 2013.

Schwanghart, W. and Scherler, D.: Short Communication: TopoToolbox 2 - MATLAB-based software for topographic analysis and modeling in Earth surface sciences, Earth Surf. Dynam., 2, 1-7, https://doi.org/10.5194/esurf-2-1-2014, 2014.

Soil Conservation Service: Urban hydrology for small watersheds, Technical release No. 55, Soil Conservation Service (SCS), Washington, DC, 1986.

Stefan, J. and Klein, A.: Hydrogeomorphic effects of beaver dams on floodplain morphology: Avulsion processes and sediment fluxes in upland valley floors (Spessart, Germany), Quaternaire, 15, 219-231, https://doi.org/10.3406/quate.2004.1769, 2004.

Stewart, J. M. and Wheatly, R. E.: Estimates of $\mathrm{CO}_{2}$ production from eroding peat surfaces, Soil Biol. Biochem., 22, 65-68, https://doi.org/10.1016/0038-0717(90)90061-4, 1990.

Suphunvorranop, T.: A guide to SCS runoff procedures, Technical publication No. 85-5, Department of Water Resources, St. Johns River Water Management District, Palatka, Florida, 1985.

Sutfin, N. A., Wohl, E. E., and Dwire, K. A.: Banking carbon: A review of organic carbon storage and physical factors influencing retention in floodplains and riparian ecosystems, Earth Surf Proc. Land., 41, 38-60, https://doi.org/10.1002/esp.3857, 2016.

Svensson, B. H.: Carbon Dioxide and Methane Fluxes from the Ombrotrophic Parts of a Subarctic Mire, Ecol. Bull., 30, 235-250, 1980. 
Swinnen, W.: Long-term dynamics of temperate peatlands in relation to environmental change and anthropogenic impact, $\mathrm{KU}$ Leuven, Leuven, Belgium, 2020.

Swinnen, W.: model code alluvial peatlands (Swinnen et al., 2021 - Biogeosciences), Mendeley Data [code], V1, https://doi.org/10.17632/vrz6gm7nhp.1, 2021.

Swinnen, W., Broothaerts, N., and Verstraeten, G.: Modelling longterm blanket peatland development in eastern Scotland, Biogeosciences, 16, 3977-3996, https://doi.org/10.5194/bg-16-39772019, 2019.

Swinnen, W., Broothaerts, N., Hoevers, R., and Verstraeten, G.: Anthropogenic legacy effects control sediment and organic carbon storage in temperate river floodplains, Catena, 195, 104897 , https://doi.org/10.1016/j.catena.2020.104897, 2020.

Terzaghi, K.: Theoretical Soil Mechanics, John Wiley and Sons, New York, 1943.

Thomas, H. and Nisbet, T. R.: An assessment of the impact of floodplain woodland on flood flows, Water Environ. J., 21, 114-126, https://doi.org/10.1111/j.1747-6593.2006.00056.x, 2007.

Tóth, B., Weynants, M., Pásztor, L., and Hengl, T.: 3D soil hydraulic database of Europe at $250 \mathrm{~m}$ resolution, Hydrol. Process., 31, 2662-2666, https://doi.org/10.1002/hyp.11203, 2017.

Treat, C. C., Kleinen, T., Broothaerts, N., Dalton, A. S., Dommain, R., Douglas, T. A., Drexler, J. Z., Finkelstein, S. A., Grosse, G., Hope, G., Hutchings, J., Jones, M. C., Kuhry, P., Lacourse, T., Lähteenoja, O., Loisel, J., Notebaert, B., Payne, R. J., Peteet, D. M., Sannel, A. B. K., Stelling, J. M., Strauss, J., Swindles, G. T., Talbot, J., Tarnocai, C., Verstraeten, G., Williams, C. J., Xia, Z., Yu, Z., Väliranta, M., Hättestrand, M., Alexanderson, H., and Brovkin, V.: Widespread global peatland establishment and persistence over the last 130,000 y, Proc. Natl. Acad. Sci. USA, 116, 4822-4827, https://doi.org/10.1073/pnas.1813305116, 2019.

Turunen, J., Tolonen, K., Tomppo, E., and Reinikainen, A.: Estimating carbon accumulation rates of undrained mires in Finland Application to boreal and subarctic regions, Holocene, 12, 6980, https://doi.org/10.1191/0959683602hl522rp, 2002.

Tuukkanen, T., Koivusalo, H., Marttila, H., Leinonen, A., Kløve, B., Laurén, A. R. I., and Finér, L.: A GIS-based model for ditch erosion risk assessment in peatland forestry, in: Erosion and Sediment Yields in the Changing Environment, International Association of Hydrological Sciences (IAHS), 221-227, 2012.

Van Asselen, S., Stouthamer, E., and Smith, N. D.: Factors controlling peat compaction in alluvial floodplains: A case study in the cold-temperate Cumberland Marshes, Canada, J. Sediment. Res., 80, 155-166, https://doi.org/10.2110/jsr.2010.015, 2010.

van Diggelen, R., Middleton, B., Bakker, J., Grootjans, A., and Wassen, M.: Fens and floodplains of the temperate zone: Present status, threats, conservation and restoration, Appl. Veg. Sci., 9, 157, https://doi.org/10.1111/j.1654-109X.2006.tb00664.x, 2006.

Van Oost, K., Verstraeten, G., Doetterl, S., Notebaert, B., Wiaux, F., Broothaerts, N., and Six, J.: Legacy of humaninduced $\mathrm{C}$ erosion and burial on soil-atmosphere $\mathrm{C}$ exchange, P. Natl. Acad. Sci. USA, 109, 19492-19497, https://doi.org/10.1073/pnas.1211162109, 2012.

VMM (Flemish Environmental Agency): Daily discharge measurements, Sint-Joris-Weert (Dijle), Flemish Environmental Agency [data set], available at: https://www.waterinfo.be/station/01L08_ 098, last access: 1 May 2021a.
VMM (Flemish Environmental Agency): Daily discharge measurements, Hulshout (Grote Nete), Flemish Environmental Agency [data set], available at: https://www.waterinfo.be/station/ 04gnt05a-1066, last access: 1 May 2021 b.

Walter, R. C. and Merritts, D. J.: Natural streams and the legacy of water-powered mills, Science (80-. )., 319, 299-304, https://doi.org/10.1126/science.1151716, 2008.

Ward, P. J., Aerts, J. C. J. H., de Moel, H., and Renssen, H.: Verification of a coupled climate-hydrological model against Holocene palaeohydrological records, Global Planet. Change, 57, 283300, https://doi.org/10.1016/j.gloplacha.2006.12.002, 2007.

Ward, P. J., Renssen, H., Aerts, J. C. J. H., van Balen, R. T., and Vandenberghe, J.: Strong increases in flood frequency and discharge of the River Meuse over the late Holocene: impacts of long-term anthropogenic land use change and climate variability, Hydrol. Earth Syst. Sci., 12, 159-175, https://doi.org/10.5194/hess-12159-2008, 2008.

Watters, J. R. and Stanley, E. H.: Stream channels in peatlands: The role of biological processes in controlling channel form, Geomorphology, 89, 97-110, https://doi.org/10.1016/j.geomorph.2006.07.015, 2007.

Wieder, R. K. and Yavitt, J. B.: Peatlands and global climate change: Insights from comparative studies of sites situated along a latitudinal gradient, Wetlands, 14, 229-238, https://doi.org/10.1007/BF03160660, 1994.

Williams, J. R., Dyke, P. T., and Jones, C. A.: EPIC - A model for assessing the effects of erosion on soil productivity, in: Analysis of Ecological Systems: State-of-the-Art in Ecological Modelling, edited by: Lauenroth, W. K., Skogerboe, G. V., and Flug, M., Elsevier, Colorado State University, Fort Collins, Colorado, USA, p. $971,1983$.

Wohl, E., Dwire, K., Sutfin, N., Polvi, L., and Bazan, R.: Mechanisms of carbon storage in mountainous headwater rivers, Nat. Commun., 3, 1263-1268, https://doi.org/10.1038/ncomms2274, 2012.

Wosten, J. H. and Ritzema, H. P.: Land and water management options for peatland development in Sarawak, Malaysia, L. Water Manag. Options, 11, 59-66, 2001.

$\mathrm{Wu}, \mathrm{J} .:$ Response of peatland development and carbon cycling to climate change: A dynamic system modeling approach, Environ. Earth Sci., 65, 141-151, https://doi.org/10.1007/s12665011-1073-1, 2012.

Young, D. M., Baird, A. J., Morris, P. J., and Holden, J.: Simulating the long-term impacts of drainage and restoration on the ecohydrology of peatlands, Water Resour. Res., 53, 6510-6522, https://doi.org/10.1002/2016WR019898, 2017.

Young, D. M., Baird, A. J., Charman, D. J., Evans, C. D., Gallego-Sala, A. V., Gill, P. J., Hughes, P. D. M., Morris, P. J., and Swindles, G. T.: Misinterpreting carbon accumulation rates in records from near-surface peat, Sci. Rep.-UK, 9, 1-8, https://doi.org/10.1038/s41598-019-53879-8, 2019.

Yu, Z., Campbell, I. D., Vitt, D. H., and Apps, M. J.: Modelling long-term peatland dynamics. I. Concepts, review, and proposed design, Ecol. Modell., 145, 197-210, https://doi.org/10.1016/S0304-3800(01)00391-X, 2001a.

Yu, Z., Turetsky, M. R., Campbell, I. D., and Vitt, D. H.: Modelling long-term peatland dynamics. II. Processes and rates as inferred from litter and peat-core data, Ecol. Modell., 145, 159173, https://doi.org/10.1016/S0304-3800(01)00387-8, $2001 \mathrm{~b}$. 